\title{
Multi-responses of O-methyltransferase genes to salt stress and fiber development of Gossypium species
}

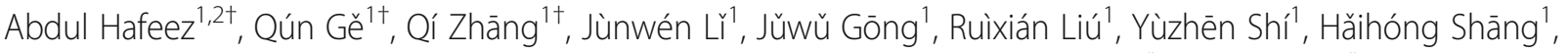 \\ Àiyīng Liú ${ }^{1}$, Muhammad S. lqbal', Xiǎoyīng Dèng ${ }^{1}$, Abdul Razzaq ${ }^{1}$, Muharam Ali² ${ }^{2 *}$ Yǒulù Yuán ${ }^{*}$ and \\ Wànkuí Gǒng ${ }^{1 *}$ (DD
}

\begin{abstract}
Background: O-methyltransferases (OMTs) are an important group of enzymes that catalyze the transfer of a methyl group from S-adenosyl-L-methionine to their acceptor substrates. OMTs are divided into several groups according to their structural features. In Gossypium species, they are involved in phenolics and flavonoid pathways. Phenolics defend the cellulose fiber from dreadful external conditions of biotic and abiotic stresses, promoting strength and growth of plant cell wall.

Results: An OMT gene family, containing a total of 192 members, has been identified and characterized in three main Gossypium species, G. hirsutum, G. arboreum and G. raimondii. Cis-regulatory elements analysis suggested important roles of OMT genes in growth, development, and defense against stresses. Transcriptome data of different fiber developmental stages in Chromosome Substitution Segment Lines (CSSLs), Recombination Inbred Lines (RILs) with excellent fiber quality, and standard genetic cotton cultivar TM-1 demonstrate that up-regulation of OMT genes at different fiber developmental stages, and abiotic stress treatments have some significant correlations with fiber quality formation, and with salt stress response. Quantitative RT-PCR results revealed that GhOMT10_Dt and GhOMT70_At genes had a specific expression in response to salt stress while GhOMT49_At, GhOMT49_Dt, and GhOMT48_At in fiber elongation and secondary cell wall stages.
\end{abstract}

Conclusions: Our results indicate that O-methyltransferase genes have multi-responses to salt stress and fiber development in Gossypium species and that they may contribute to salt tolerance or fiber quality formation in Gossypium.

Keywords: O-methyltransferase, Gossypium, Fiber development, Biotic and abiotic stress

\footnotetext{
*Correspondence: ali_aflp@yahoo.com; yuanyoulu@caas.cn;

gongwankui@caas.cn

${ }^{\dagger}$ Abdul Hafeez, Qún Gě and Qí Zhāng contributed equally to this work.

${ }^{2}$ Sindh Agriculture University Tandojam, Hyderabad, Sindh 70060, Pakistan

${ }^{1}$ State Key Laboratory of Cotton Biology, Institute of Cotton Research,

Chinese Academy of Agricultural Sciences, Anyang 455000, Henan, China
}

(C) The Author(s). 2021 Open Access This article is licensed under a Creative Commons Attribution 4.0 International License, which permits use, sharing, adaptation, distribution and reproduction in any medium or format, as long as you give appropriate credit to the original author(s) and the source, provide a link to the Creative Commons licence, and indicate if changes were made. The images or other third party material in this article are included in the article's Creative Commons licence, unless indicated otherwise in a credit line to the material. If material is not included in the article's Creative Commons licence and your intended use is not permitted by statutory regulation or exceeds the permitted use, you will need to obtain permission directly from the copyright holder. To view a copy of this licence, visit http://creativecommons.org/licenses/by/4.0/. The Creative Commons Public Domain Dedication waiver (http://creativecommons.org/publicdomain/zero/1.0/) applies to the data made available in this article, unless otherwise stated in a credit line to the data. 


\section{Background}

Cotton (Gossypium Species) has the importance for natural fiber all over the globe. The primary goals of upland cotton (G. hirsutum) perspectives have been always to achieve better quality with higher yield [1]. Mostly $G$. hirsutum bears staple fibers $25-40 \mathrm{~mm}$ in length and $15 \mu \mathrm{m}$ in thickness at their full maturity. Fiber cells must undergo four distinct but partially overlapped developmental stages, including initiation, elongation, secondary cell wall deposition, and maturation. The secondary cell wall of fiber, which is mainly composed of cellulose, is important especially for fiber quality perspective. However, some studies have shown that secondary cell wall of fibers of flax (Linum usitatissimum L.), ramie (Boehmeria nivea L.), and Spanish broom (Spartium junceum L.) also contain phenolics along with cellulose. Their fibers are known for their physical properties such as length and strength and have been used for textile purposes. A thicker secondary cell wall was estimated to contain no less than $70 \%$ cellulose content while the cotton fiber contains almost $90 \%$ cellulose [2, 3]. Lignin is another important component in cell wall [4]. It provides strength to plant cell wall and response to biotic and abiotic stresses in vascular plants [5]. The presence of lignin, which is reported at lower level in secondary cell wall of cotton fibers [6], negatively regulates fiber elongation and secondary cell wall synthesis in cotton. Studies demonstrated that the cotton plants that accumulate less lignin and lignin-like phenolics in mature fibers tend to have longer and stronger fibers [7]. From an active perspective, lignin and phenolics defend the cellulose fiber against dreadful conditions and increase the ability of response to biotic and abiotic stresses, and thus influence the growth and strength of plant cell walls [8]. Previous studies in herbaceous plants demonstrated the involvement of O-methyltransferases (OMTs) in lignin biosynthesis [9]. The involvement of OMTs mediate normal plant growth in the presence of lignin [10]. The initial OMT cDNA was described in 1991 [11], then a series of OMT cDNAs have been cloned from diverse plants species, including Zea mays, Arabidopsis thaliana, Iris hollandica, and Nicotiana tabacum [12].

According to substrate classification, plant methyltransferases have three major categories, I. O-methyltransferases $(O M T s)$, II. N-methyltransferases (NMTs), and III. Cmethyltransferases $(C M T s)$. Category I OMTs are further classified into five sub-categories. Sub-category I-a comprises caffeoyl coenzyme A 3-O-methyltransferase (CCOAOMT) and caffeic acid 3-O-methyltransferases (COMTs), which are involved in methylation in phenylpropanoids. Sub-categories I-b, I-c, and I-d act in methylation of hydroxyl in flavonoid, alkaloids, and myoinositol, respectively. The fifth subcategory I-e takes part in methylation of carboxyl of diverse acids. The results of a study discovered the crystal structure of OMTs from Medicago sativa [13]. In the light of the explanations, the $O M T$ gene that was cloned and characterized from a medicinal plant Ligusticum chuanxiong and contained higher ferulic acid was named as $L c C O M T$. The differential expression of $L c C O M T$ gene under chilling stress was more than 6-fold higher than that under controlled conditions, suggesting that ferulic acid may increase plant tolerance to cold stress. BLAST analysis showed that LcCOMP was 23.9$40.2 \%$ similar to OMTs of alkaloid, flavonoid, isoflavonoid, and phenylpropanoids [14].

In the whole life cycle of cotton plant, it undergoes various environmental conditions from the cold spring in April when it is sowed to hot mid-summer when it grows rapidly in vegetation and reproduction and to late freezing autumn when it gets mature and is harvested. During the whole growth procedure, the cotton plant maintains an exquisite molecular controls and regulations. But little is known what roles the OMT family genes have played in cotton plant especially in early or late growth stage when season transition occurs, or in various stress conditions. Therefore, in this study, we identified the $O M T$ family genes in the genome-wide scale and made detailed bioinformatics analysis of gene structure, chromosomal distribution, selection pressure during their evolution, sub-cellular localization, cisregulatory elements etc., together with their expression profiling in different developmental stages and in responses to various stresses. Their expression profiling in developing fiber cells was verified using RNA sequencing data from RILs, CSSLs, and TM-1 at different fiber development stages. This study could open the way to comprehend the functions of OMTs in fiber quality advancement and in cotton plant responses to abiotic stresses, and thus could assume a noteworthy part for further investigation in the molecular mechanism of fiber improvement and stress tolerance.

\section{Results}

Genomewide identification and characterization of OMT genes

A genome wide analysis was conducted to characterize OMT family genes in three Gossypium species. A total of 192 OMT members were identified, including 82 in G. hirsutum, 55 in G. arboreum, and 55 in G. raimondii (Table S3. Sheet A). For phylogenetic analysis [15], 33 OMT members in A. thaliana, and 26 members in T. cacao species were also retrieved (Table S3. Sheet B). Retrieving information of OMT genes in G. hirsutum revealed that GhOMT75_Scaf, which was detected in scaffold, coded the smallest protein of 62 amino acids (aa) with a molecular weight of $6.642 \mathrm{kDa}$. While GhOMT33_Dt, which was identified on chromosome $\mathrm{D}_{\mathrm{t}} 02$, coded the largest protein of 969 aa with a molecular weight of $108.296 \mathrm{kDa}$ among all $O M T$ members in three Gossypium species. 
In domain analysis of OMT family genes in Gossypium species, the results revealed that 64, 45 and 47 OMTs in G. hirsutum, G. arboreum and G. raimondii contained Pfam domain Pf00891, and that only 20, 10 and 9 OMTs in G. hirsutum, G. arboreum and G. raimondii contained Pfam domain Pf01596. In A. thaliana and T. cacao, 25, 24 OMTs contained Pf00891 domain, and 8, 2 OMTs contained Pf01596 domain respectively.

\section{Chromosomal distribution, collinearity, duplication, and loss of OMT genes}

The analysis of chromosomal positioning was performed by using TBtools software [16]. A total of 161OMT genes were positioned on their respective chromosomes, while seven of G. raimondii, one of G. arboreum, and 23 of G. hirsutum were positioned in scaffolds (Figure S1). In G. raimondii (D genome), chr11 was mapped with 13 genes followed by chr08 with nine genes. The minimum number of genes in a chromosome was one in chr2, chr6, and chr10 respectively. There was no OMT family members identified in chr01 and chr07 (Figure S1.a). In G. arboreum (A-genome) (Figure S1.b), 54 OMT genes were mapped in all chromosomes except chr1. Chr10 harbored $13 O M T$ genes which were the highest per chromosome, followed by chr12 and chr04 with 10 and 9 genes respectively. The minimum number of genes located in a chromosome was one in chr02 and chr11 respectively. In G. hirsutum ( $\mathrm{A}_{\mathrm{t}} \mathrm{D}_{\mathrm{t}}$ genome) (Figure S1.c), unexpectedly, there were no OMT genes in $\mathrm{A}_{\mathrm{t}} 02, \mathrm{~A}_{\mathrm{t}} 05, \mathrm{~A}_{\mathrm{t}} 07, \mathrm{D}_{\mathrm{t}} 03, \mathrm{D}_{\mathrm{t}} 09$, and $D_{t} 11$ chromosomes. The distribution of genes in $D_{t}$ sub-genome (33 genes) was higher than in $A_{t}$ subgenome (26 genes). The maximum number of genes in a chromosome was seven in $\mathrm{D}_{t} 04$ and $\mathrm{A}_{t} 12$, followed by four in $D_{t} 10$ and $A_{t} 10$ chromosomes, respectively. $D_{t} 01$, $\mathrm{D}_{t} 05, \mathrm{~A}_{t} 01, \mathrm{~A}_{t} 06$, and $\mathrm{A}_{t} 11$ only had one OMT gene, and $\mathrm{D}_{t} 06, \mathrm{D}_{\mathrm{t}} 07, \mathrm{~A}_{\mathrm{t}} 03, \mathrm{~A}_{\mathrm{t}} 08, \mathrm{~A}_{\mathrm{t}} 09, \mathrm{~A}_{\mathrm{t}} 13$ two OMT genes and $\mathrm{D}_{\mathrm{t}} 02, \mathrm{D}_{\mathrm{t}} 08$, and $\mathrm{D}_{\mathrm{t}} 13$ three $O M T$ genes respectively (Figure S1.c). A collinearity analysis of the OMT family genes in Gossypium species chromosomes was shown in Fig. 1. The results demonstrated a pair wise collinearity of $O M T$ genes between the chromosomes on which $O M T$ family genes were mapped. Noticeably, a number of available genes in $A_{t}$ and $D_{t}$ scaffolds were collinear with their homologues in $\mathrm{A}$ and $\mathrm{D}$ genomes suggesting the collinearity of the DNA fragments between the scaffolds and chromosome where these OMT genes locate (Fig. 1). Taken the OMT gene numbers identified in each $A / D$ genome or $A_{t} / D_{t}$ sub-genome, collinearity analysis also revealed that there were totally 21 and 19 OMT genes exclusively detected in A and D genomes respectively. Their homologous counterparts in $A_{t} D_{t}$ genomes of $G$. hirsutum are lost. There are also a few $O M T$ genes that are exclusively detected in $A_{t} D_{t}$ genome of G. hirsutum without homologous counterparts in A and D genomes (Figure S1).

According to previous studies there are five types of duplications including singleton, dispersed, proximal, tandem, and segmental or whole-genome duplication [17]. In the present study, the analysis of gene pairs duplication events predicted a total of 31,28 , and 54 gene pairs of D_D,$A_{-} A_{t}$ and $D \_A$ genomes from their common ancestor, 33 gene pairs of $A_{t} D_{t}$ subgenomes in segmental duplication, and 5 gene pairs of $A_{t} D_{t}$ subgenomes in tandem duplication events (Table S4 Sheet A).

\section{Analysis of selection pressure}

In genetics, the $\mathrm{Ka} / \mathrm{Ks}$ ratio used to estimate the balance between neutral mutations, purifying selections, and positive mutations based on a set of homologous genes [18]. The ratio of the number of non-synonymous substitutions per non-synonymous site (Ka) to the number of synonymous substitutions per synonymous site (Ks) represents selection pressure of the gene [19]. $\mathrm{Ka} / \mathrm{Ks}<1$ demonstrates purifying selection pressure, while $\mathrm{Ka} / \mathrm{Ks}=$ 1 and $\mathrm{Ka} / \mathrm{Ks}>1$ show neutral and positive selection pressures respectively. Analysis of $\mathrm{Ka} / \mathrm{Ks}$ ratio of homologous OMTs in three Gossypium species revealed that they are under purifying selection pressure. The $\mathrm{Ka} / \mathrm{Ks}$ ratio of homologous OMTs in G. raimondii and G. arboreum ranged from 0.09 to 0.8 , in G. raimondii and G. hirsutum ranged 0 to 0.7 , and in $A_{t}$ and $D_{t}$ of G. hirsutum ranged 0.4 to 0.7 (Table S4 Sheet $B$ ).

\section{Sequences alignment, phylogenetic analyses, conserved motifs and gene structure}

The sequence alignment of $251 O M T$ genes, including 192 genes from three Gossypium species, 33 from $A$. thaliana, and 26 from T. cacao species was performed to understand the phylogenetic relationship of these genes. The evolutionary relationship of OMT genes in three Gossypium species was monophyletic (Fig. 2a), and the member of A. thaliana and T. cacao were distributed in paraphyletic manner (Fig. 2b). According to the topology of constructed tree, the OMT gene family is divided into five clades (I, II, III, IV, and V) in Gossypium, A. thaliana, and T. cacao species. The results showed that each clade of $O M T$ genes were symmetrically distributed within Gossypium species (Fig. 2a), while in $A$. thaliana and T. cacao, OMT genes were identified in cluster forms (Fig. 2b). The results demonstrated that these Gossypium OMT members might be evolutionary close within respective species and their identified clades.

To examine the conserved motifs of each clade, the analysis of representative motif logo and conserved motifs prediction were conducted (Figure S2). The results 


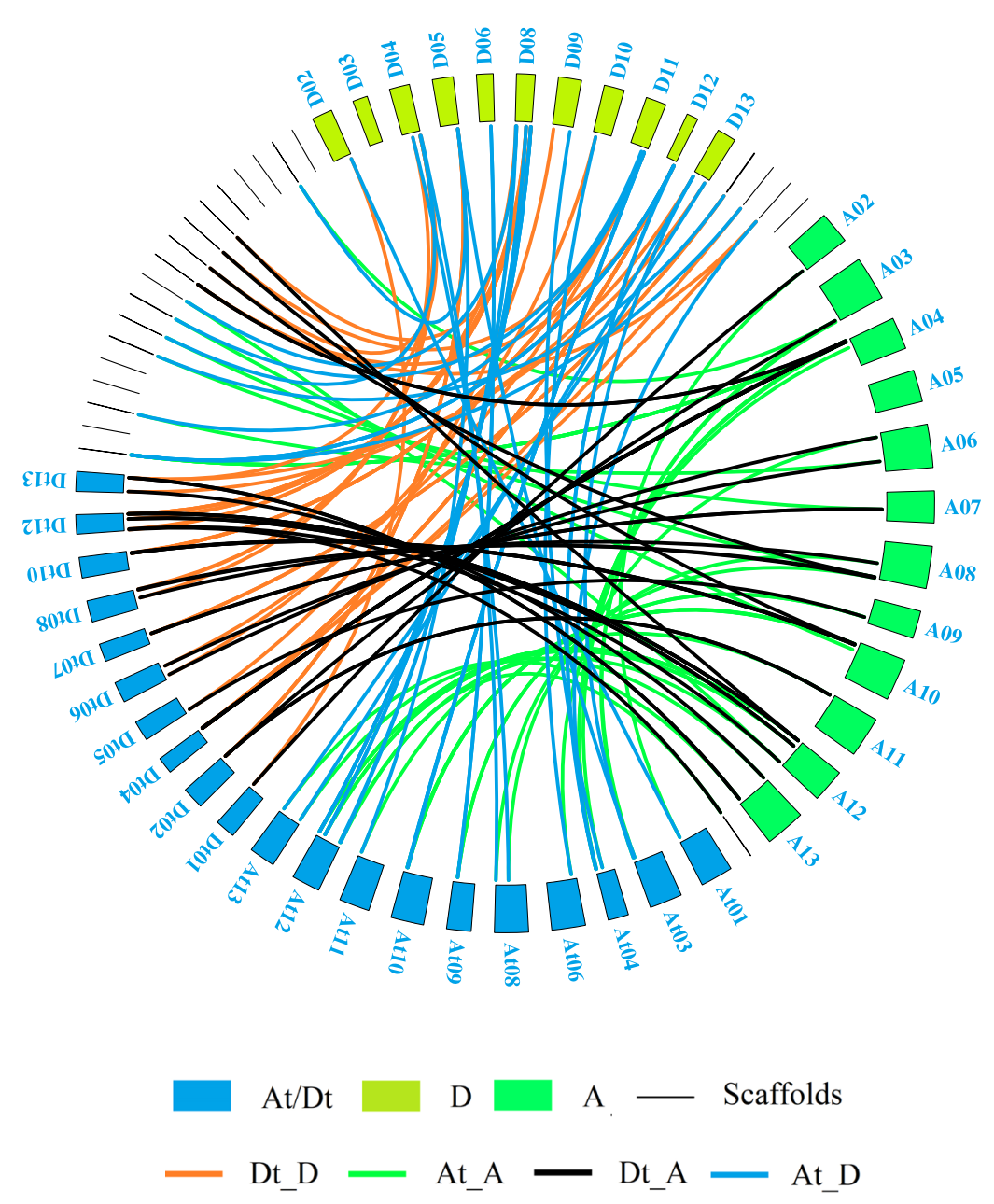

Fig. 1 Collinearity analysis of OMT genes between $A_{t} D_{t}$ (G. hirsutum), A (G. arboreum), and D (G. raimondii) genomes

revealed that motif 1 , enriched with leucine, valine, and glycine, motif 2, enriched with leucine and valine, and motif3, motif 4 , motif 5 , and motif 6 were common in clades I, II, III, IV and clade V. While motif 7 was found missing in some members of clade $\mathrm{V}$, which was then replaced with motif 8 at same positions (Figure S2). The enriched amino acid residues of conserved motif1 (L/ VDVGGG/TG) was previously identified in S-adenosyll-methionine (SAM)-dependant OMTs that shared 95\% similarity with G. hirsutum OMT [20].

Investigation of gene structure has uncovered the different number of exons and introns of $O M T$ genes. Exon and intron number of $O M T$ genes varied from the least one exon and no intron to the most 7 to 9 exons and 6 to 8 introns (Table S5). Two members in G. hirsutum including GhOMT82_At and GhOMT82_Dt contain nine exons as the highest (Table S5). Same as, two members including GaOMT82_A in G. arboreum, and GrOMT82_D in G. raimondii contain 9 exons (Table S5). Gene structure analysis revealed that the $O M T$ genes with higher number of exons had a shorter exons and introns, and vice versa. These results demonstrated that $O M T$ members possess different structural patterns in accordance with their features.

\section{Identification of cis-regulatory elements in OMT family}

The promoter regions of the $O M T$ family contain precisely a large number of cis-regulatory elements. The analysis of cis-regulatory elements revealed the enrichment of MYB cis-regulatory elements, which was detected more than 350 times in OMT genes (Figure S3). The MYC was another important element that was found 183 times in enlisted OMT genes. Box 4 (part of a conserved DNA module involved in light responsiveness) was found 152 times in 43/82 genes in G. hirsutum. ABRE elements was detected 119 times in 29/82 OMT genes in G. hirsutum. The ERE element was detected 113 times in 37/82 and G- 


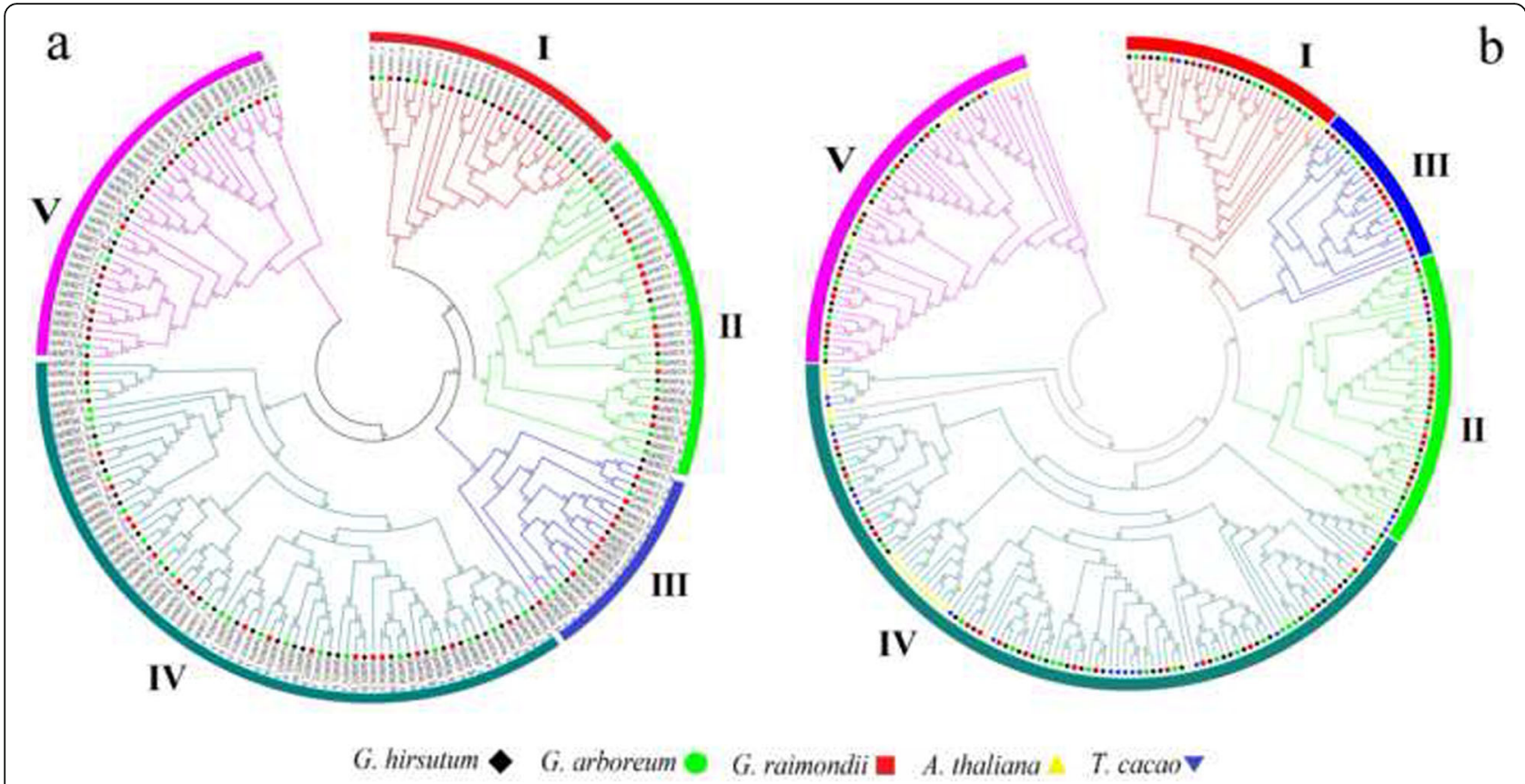

Fig. 2 Phylogenetic analysis of OMT genes in Gossypium, A. thaliana, and T. cacao species. a Neighbor-joining phylogenetic tree of 192 OMT genes of G. hirsutum, G. arboreum, and G. raimondii. b Neighbor-joining phylogenetic tree of 251 OMT sequences of G. hirsutum, G. arboreum, G. raimondii, A. thaliana, and T. cacao. I, II, III, IV and V indicate the five groups of phylogenetic tree. Shapes with different colors represent OMT members of G. hirsutum, G. arboreum, G. raimondii, A. thaliana, and T. cacao

Box 97 times in 37/82 G. hirsutum OMT genes. An auxin RR-core and cis-acting regulatory element involved in the MeJA-responsiveness (TGACG-motif) were also observed in Gossypium OMT genes where this element was identified 48 times in 25/82 genes. Some other important cis-regulatory elements including wun-motif 44 times in 26/82, W-box 39 times in $31 / 82$, GATA-motif 32 times in 27/82, O2-site 30 times in 22/82 OMT genes respectively, in G. hirsutum (Figure S3). These cis-regulatory elements might function collectively in accordance with their specific roles and with specific conditions as well as growth and development stages (Figure S3).

\section{Sub-cellular localization prediction of OMT genes}

Understanding and determining the sub-cellular localization of proteins is an important strategy to identify the function of protein at cellular level [21]. This approach includes proteomic-based experiments and microscopic high throughputs [22, 23]. Several sequence-based approaches have been developed to predict the sub-cellular localization by providing amino acid sequences including PSORT [24], Yloc [25], BaCelLO [26], LOCtree [27]. According to CELLO prediction, most of OMT genes were located in the cytoplasm (Table 1), while seven genes were predicted in periplasm, including, GhOMT45_At, GhOMT45_Dt, GhOMT46_Dt, GhOMT48_At, GhOMT48_Dt, GhOMT49_At, and
GhOMT49_Dt. Five OMTs were predicted to be localized in both periplasm and cytoplasm, including GhOMT47_At, GhOMT47_Dt, GhOMT53_At, GhO MT54_Dt, and GhOMT68_At. Two genes GhOMT82_At and GhOMT82_Dt were predicted in the outer membrane. Only GhOMT55_At was predicted in inner membrane and cytoplasm (Table. 1). The results of Wolf Psort were highly in agreement with those of CELLO analysis regarding the presence of most of the OMT genes in cytoplasm, however, with exceptions of GhOMT48_At, GhOMT82_At, GhOMT82_Dt, which were predicted in chloroplast and one gene GhOMT76 $D t$ in mitochondria (Table. 1). The function of the OMT genes might be related to their predicted localizations, though the experimental approach is still needed for further confirmation.

\section{GO enrichment and KEGG pathway analyses}

To understand the functional annotations of $O M T$ family genes of G.hirsutum, 82 genes in G. hirsutum were undergone through gene ontology (GO) enrichment, kyoto encyclopedia of genes and genomes (KEGG Pathway), and InterPro analyses. GO term analysis verified their O-methyltransferase activity of all $82 O M T$ genes, while 62 of the 82 genes were also enriched in methyltransferase activity and 53 of the 82 genes in protein dimerization activity (Fig. 3a). KEGG Pathway analysis revealed that these OMTs 
Table 1 Predicted Subcellular localization of OMT genes of G. hirsutum

\begin{tabular}{|c|c|c|c|c|c|c|c|c|c|}
\hline Gene ID & CELLO & C_Reliability & Wolf Psort & P_Reliability & Gene ID & CELLO & C_Reliability & Wolf Psort & P_Reliability \\
\hline GhOMT51_At & $\mathrm{Cp}$ & 3.712 & $C p$ & 1 & GhOMT10_Dt & $\mathrm{Cp}$ & 3.384 & $C p$ & 6 \\
\hline GhOMT33_At & $\mathrm{Cp}$ & 3.597 & $C p$ & 9.5 & GhOMT7_Dt & $\mathrm{Cp}$ & 4.717 & $C p$ & 11 \\
\hline GhOMT74_At & $\mathrm{Cp}$ & 2.985 & $C p$ & 7 & GhOMT8_Dt & $\mathrm{Cp}$ & 4.717 & $C p$ & 7 \\
\hline GhOMT40_At & $\mathrm{Cp}$ & 3.897 & $C p$ & 12 & GhOMT9_Dt & $C p$ & 4.735 & $C p$ & 9 \\
\hline GhOMT68_At & $\mathrm{Pp} / \mathrm{Cp}$ & $2.094 / 2.624$ & $C p$ & 6 & GhOMT79_Dt & $\mathrm{Cp}$ & 3.973 & $C p$ & 10 \\
\hline GhOMT71_At & $\mathrm{Cp}$ & 4.545 & $\mathrm{Cp}$ & 5 & GhOMT81_Dt & $\mathrm{Cp}$ & 3.924 & $C p$ & 6.5 \\
\hline GhOMT78_At & Cp & 4.122 & $C p$ & 13.5 & GhOMT78_Dt & Cp & 2.531 & $C p$ & 2 \\
\hline GhOMT81_At & $\mathrm{Cp}$ & 2.707 & $C p$ & 5 & GhOMT54_Dt & $\mathrm{Pp} / \mathrm{Cp}$ & $1.967 / 2.566$ & $C p$ & 8 \\
\hline GhOMT3_At & $C p$ & 4.033 & $\mathrm{Cp}$ & 2 & GhOMT76_Dt & $\mathrm{Cp}$ & 3.273 & $\mathrm{Mc}$ & 8 \\
\hline GhOMT10_At & $\mathrm{Cp}$ & 4.822 & $C p$ & 6 & GhOMT32_Dt & $\mathrm{Cp}$ & 4.607 & $C p$ & 12 \\
\hline GhOMT12_At & $\mathrm{Cp}$ & 4.154 & $\mathrm{Cp}$ & 4 & GhOMT30_Dt & $\mathrm{Cp}$ & 3.946 & $\mathrm{Cp}$ & 1 \\
\hline GhOMT6_At & $\mathrm{Cp}$ & 4.234 & $C p$ & 8 & GhOMT31_Dt & $\mathrm{Cp}$ & 4.695 & $C p$ & 6 \\
\hline GhOMT76_At & $\mathrm{Cp}$ & 4.275 & $\mathrm{Cp}$ & 11.5 & GhOMT49_Dt & $\mathrm{Pp}$ & 3.275 & $\mathrm{Cp}$ & 8 \\
\hline GhOMT32_At & Cp & 4.675 & Cp & 8 & GhOMT57_Dt & $\mathrm{Cp}$ & 4.391 & $C p$ & 7 \\
\hline GhOMT30_At & $\mathrm{Cp}$ & 4.743 & $C p$ & 6 & GhOMT77_Dt & $\mathrm{Cp}$ & 2.352 & $C p$ & 3 \\
\hline GhOMT49_At & $\mathrm{Pp}$ & 3.107 & $\mathrm{Pp}$ & 11 & GhOMT58_Dt & $C p$ & 4.675 & $C p$ & 5 \\
\hline GhOMT77_At & $\mathrm{Cp}$ & 3.838 & $C p$ & 7 & GhOMT63_Dt & $\mathrm{Cp}$ & 3.572 & $C p$ & 10 \\
\hline GhOMT57_At & $\mathrm{Cp}$ & 2.229 & $\mathrm{Cp}$ & 9 & GhOMT62_Dt & $\mathrm{Cp}$ & 2.968 & $C p$ & 4 \\
\hline GhOMT52_At & Cp & 1.577 & $C p$ & 10 & GhOMT61_Dt & $C p$ & 3.224 & $C p$ & 4 \\
\hline GhOMT53_At & $\mathrm{Pp} / \mathrm{Cp}$ & $1.995 / 1.743$ & $\mathrm{Cp}$ & 6.5 & GhOMT17_Dt & $\mathrm{Cp}$ & 4.112 & $C p$ & 2 \\
\hline GhOMT62_At & Cp & 3.577 & $C p$ & 2 & GhOMT13_Dt & Cp & 4.124 & $C p$ & 7 \\
\hline GhOMT65_At & $\mathrm{Cp}$ & 3.508 & $C p$ & 8 & GhOMT70_Dt & $\mathrm{Cp}$ & 4.385 & $C p$ & 13 \\
\hline GhOMT24_At & $\mathrm{Cp}$ & 4.529 & $C p$ & 8 & GhOMT1_Dt & $\mathrm{Cp}$ & 4.927 & $C p$ & 10 \\
\hline GhOMT14_At & $\mathrm{Cp}$ & 4.404 & $C p$ & 12 & GhOMT55_Dt & $\mathrm{Cp}$ & 2.781 & $C p$ & 1 \\
\hline GhOMT29_At & $\mathrm{Cp}$ & 4.069 & $C p$ & 1 & GhOMT82_Dt & $\mathrm{OM}$ & 2.226 & Chp & 9 \\
\hline GhOMT41_At & $\mathrm{Cp}$ & 4.655 & $C p$ & 6 & GhOMT45_Dt & $\mathrm{Pp}$ & 3.910 & $C p$ & 6 \\
\hline GhOMT70_At & Cp & 3.408 & $C p$ & 8 & GhOMT46_Dt & $\mathrm{Pp}$ & 2.490 & $C p$ & 10 \\
\hline GhOMT1_At & $C p$ & 4.921 & $\mathrm{Cp}$ & 7 & GhOMT47_Dt & $\mathrm{Pp} / \mathrm{Cp}$ & $1.961 / 2.316$ & $C p$ & 10 \\
\hline GhOMT55_At & IM/Cp & $1.807 / 2.478$ & $C p$ & 1 & GhOMT48_Dt & $\mathrm{Pp}$ & 4.276 & $C p$ & 8 \\
\hline GhOMT82_At & $\mathrm{OM}$ & 2.374 & Chp & 9.5 & GhOMT72_Dt & $\mathrm{Cp}$ & 4.474 & $\mathrm{Cp}$ & 11.5 \\
\hline GhOMT45_At & $\mathrm{Pp}$ & 4.340 & $C p$ & 7 & GhOMT60_Dt & $\mathrm{Cp}$ & 4.312 & $C p$ & 7 \\
\hline GhOMT47_At & $\mathrm{Pp} / \mathrm{Cp}$ & $2.121 / 2.358$ & $C p$ & 12 & GhOMT59_Dt & $\mathrm{Cp}$ & 4.534 & $C p$ & 6 \\
\hline GhOMT48_At & $\mathrm{Pp}$ & 4.154 & Chp & 6 & GhOMT5_Scaf & $\mathrm{Cp}$ & 4.641 & $C p$ & 11 \\
\hline GhOMT2_At & $\mathrm{Cp}$ & 4.870 & $C p$ & 5 & GhOMT11_Scaf & $\mathrm{Cp}$ & 4.885 & $C p$ & 4 \\
\hline GhOMT72_At & $\mathrm{Cp}$ & 4.493 & $C p$ & 13.5 & GhOMT68_Scaf & $\mathrm{Cp}$ & 3.973 & $C p$ & 8 \\
\hline GhOMT60_At & $\mathrm{Cp}$ & 4.637 & $C p$ & 5 & GhOMT52_Scaf & $\mathrm{Cp}$ & 2.277 & $C p$ & 4 \\
\hline GhOMT51_Dt & $C p$ & 3.636 & $C p$ & 2 & GhOMT46_Scaf & $\mathrm{Cp}$ & 2.154 & $C p$ & 11 \\
\hline GhOMT37_Dt & $\mathrm{Cp}$ & 4.092 & $C p$ & 6 & GhOMT15_Scaf & $\mathrm{Cp}$ & 3.576 & $C p$ & 9 \\
\hline GhOMT35_Dt & $\mathrm{Cp}$ & 4.228 & $C p$ & 4 & GhOMT75_Scaf & $\mathrm{Cp}$ & 2.090 & $\mathrm{Cp}$ & 5 \\
\hline GhOMT33_Dt & Cp & 3.130 & $C p$ & 8 & GhOMT73_Scaf & Cp & 3.123 & $C p$ & 6 \\
\hline GhOMT71_Dt & $\mathrm{Cp}$ & 4.475 & $C p$ & 11.5 & & & & & \\
\hline GhOMT6_Dt & $C p$ & 4.619 & $C p$ & 8 & & & & & \\
\hline
\end{tabular}

Cp: Cytoplasmic, Pp: Periplasmic, OM: outer membrane, IM: inner membrane, Chp: Chloroplast, Mc: Mitochondria C_Reliability: Lower reliability values show the stronger possibility of predicted localization

P_Reliability: Higher reliability values show the stronger possibility of predicted localization 
were involved in different metabolic pathways. Twenty-nine OMTs were involved in monolignol biosynthesis, phenylpropanoid, secondary metabolism, and metabolic pathways respectively. Eleven genes were involved in phenylalanine and flavonoid biosynthesis pathways respectively (Fig. 3b). InterPro analysis (http://www.ebi.ac.uk/interpro/) categorized these $82 O M T$ genes as functional genes of S-adenosyl-Lmethionine-dependent methyltransferase (Fig. 3c). Sixtytwo genes were also predicted in categories of methyltransferase_2 and O-methyltransferase COMT-type respectively (Fig. 3c), while fifty-seven in winged helix-turn-helix DNAbinding domain, fifty-three in plant methyltransferase dimerization (Fig. 3c).

\section{Expression profiling of $O M T$ genes and their homologues in fiber development and salt stress}

In order to verify the biological functions of $O M T$ family genes, several transcriptome data sets including TM-1 [28], G. arboreum, G. raimondii, CSSLs [29], and RILs [30], were applied to analyze their expression profiles in different developmental stages, organs, or tissues, and responses to various abiotic stress treatments. The transcriptome clusters showed that the OMT genes can be assorted into three basic groups (Fig. 4a): Those that have a broad responses to different developmental stages from germination to fiber maturation, typical examples of which included GhOMT48_At, GhOMT48_Dt, GhOMT49_At and GhOMT49_Dt; those that have specific responses to root development, including GhOMT1_At, GhOMT2-At and GhOMT40_At; and those that have responses to early germination in seed, cotyledon, root and stem, including
GhOMT47_At, GhOMT9_Dt, and GhOMT58_Dt. When fiber specific transcriptome data sets of G. arboreum, G. raimondii were applied to observe the expression profiling diploid OMT family genes, the result also supported specific expression profiling of some $O M T$ genes in diploid species of G. arboreum (Fig. 4b) and G. raimondii (Fig. 4c).

The gene expression profiling was further verified with trancriptome datasets of RILs (Fig. 5a) two CSSLs (Fig. 5b and c). The results showed that the genes that had specific expressions during fiber development (Fig. 4a) also had specific expressions in fiber development of RILs and CSSLs materials. These genes had a highly consistent expression profiling among the different cotton cultivars and lines during fiber development. Some selected GhOMT examples genes, GhOMT49_At (Fig. 5d), GhOMT70_At (Fig. 5e), GhOMT48_At (Fig. 5f), GhOMT10_Dt (Fig. 5g), and GhOMT49_Dt (Fig. 5h), were verified through qRT-PCR using sGK9708 and 0-153, the two parental lines of the RIL population with different fiber quality traits. The results showed that GhOMT48_At, GhOMT49_At, and GhOMT49_Dt were significantly up-regulated during fiber development in sGK9708 than in 0-153 Fig. 5d, f and h) and that GhOMT70_At and GhOMT10_Dt did not show differences between the two cultivars (Fig. 5e and g). Noticeably, GhOMT49_At and GhOMT49_Dt reached the highest expression levels at 20 DPA and their high expression lasted in a short time as compared with that of GhOMT48_At.GhOMT48_At had a rapid expression increase from 10 DPA to 15DPA and then its expression steadily increased until 25 DPA when it reached its highest expression level.

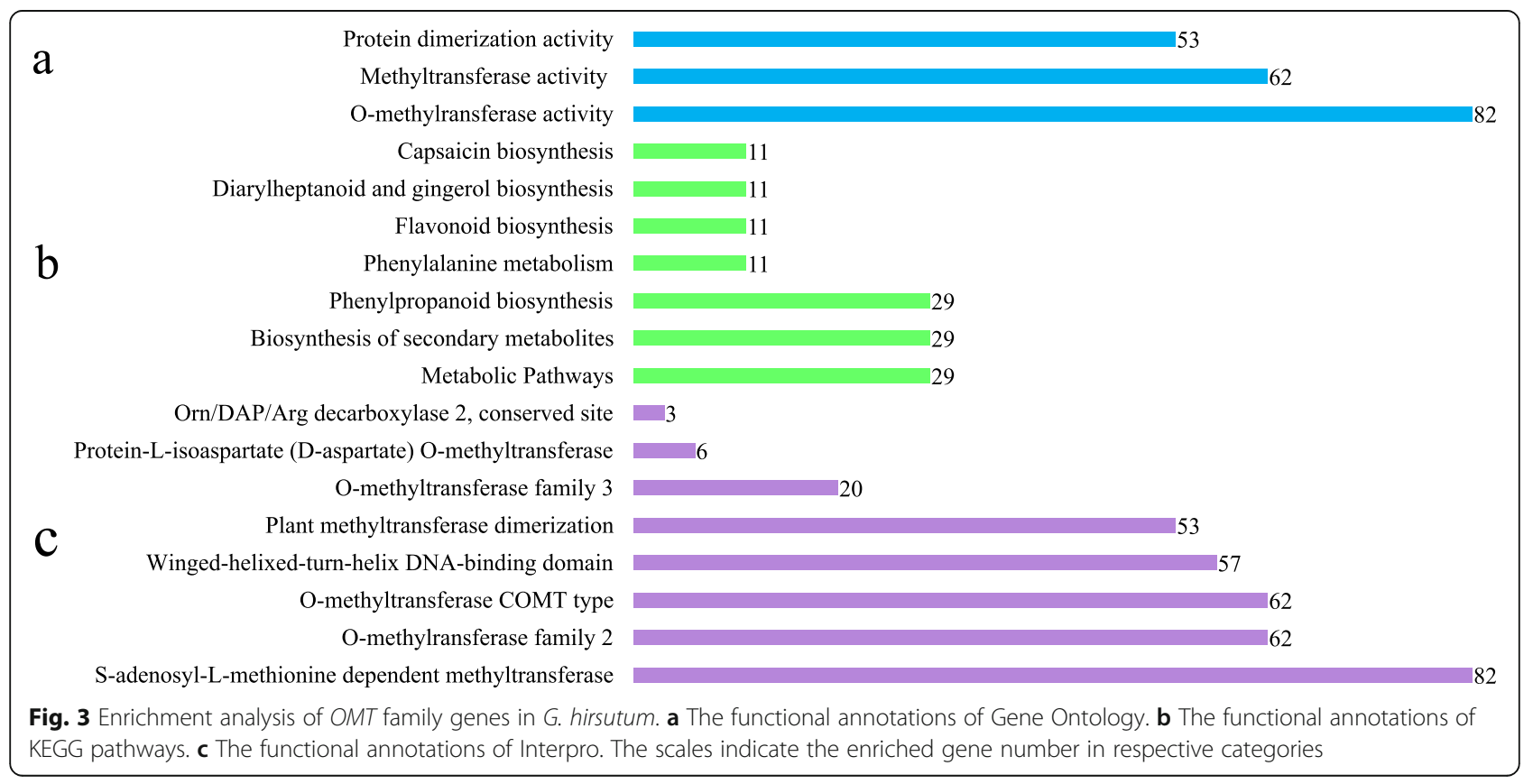




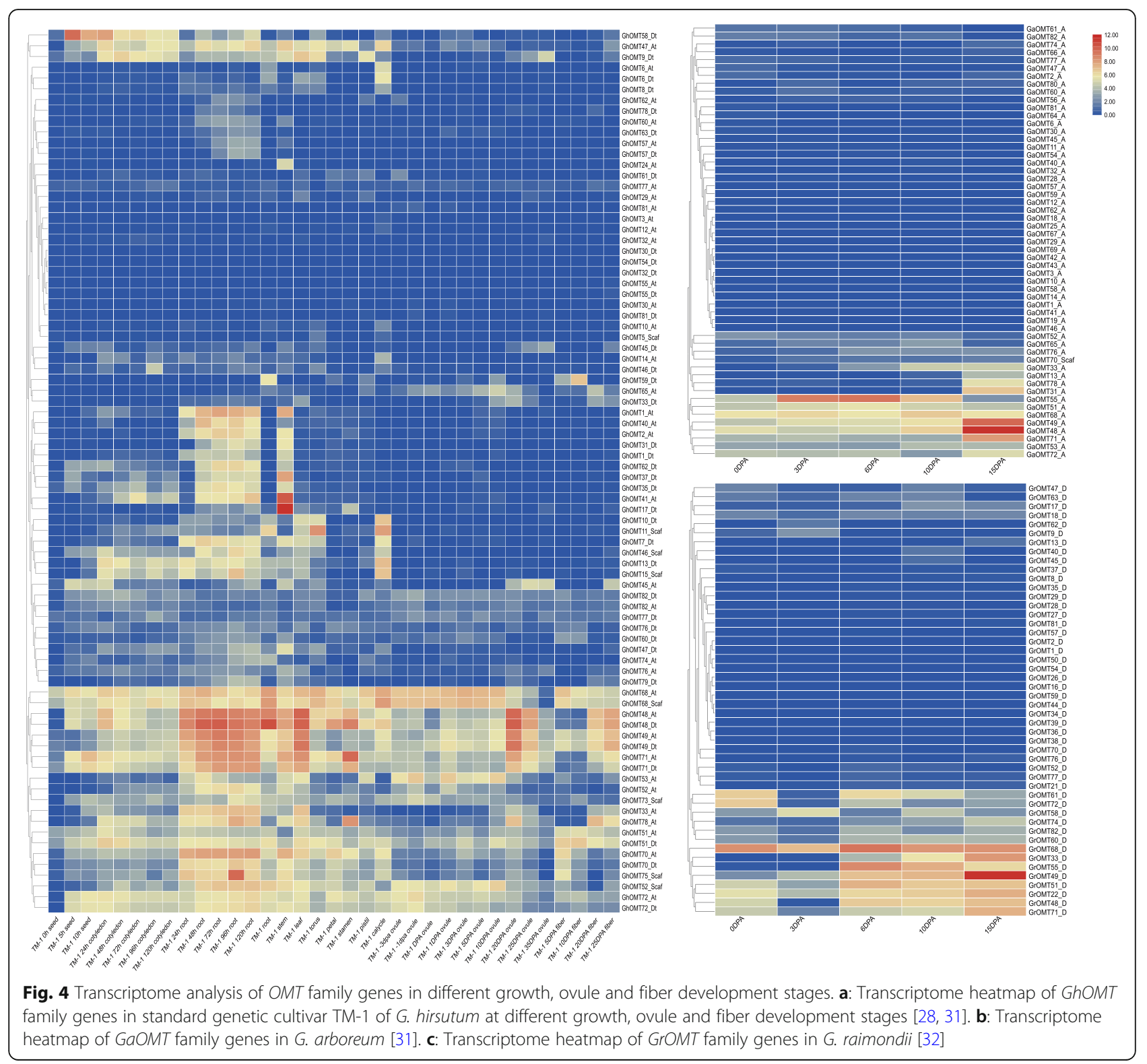

Based on the expression profiling of the OMT gene family in responses to cold, hot, osmotic, and salt stress treatments (Fig. 6a), two genes specific in salt stress responses, GhOMT70_At and GhOMT10_Dt, and three genes specific in fiber development, GhOMT48_At, GhOMT49_At, and GhOMT49_Dt, were verified by qRT-PCR with RNA samples extracted from salt treatment. The results indicated that both GhOMT70_At and GhOMT10_Dt showed an elevated expression in salt treatments in salt-tolerant cultivar as compare to the control treatments (Fig. 6b and c). These two genes had different expression profiles from $2 \mathrm{~h}$ to $6 \mathrm{~h}$ after salt treatment. GhOMT70_At had the highest expression at $2 \mathrm{~h}$ and then its expression went down at $6 \mathrm{~h}$; whereas GhOMT10_Dt had an increasing expression pattern from $2 \mathrm{~h}$ to $6 \mathrm{~h}$. Both genes had much higher expression in roots than in stem or leaf.

\section{Discussion}

\section{A genome-wide survey of OMTs}

A genome wide search of G. hirsutum [28], G. arboreum [35], and G. raimondii [36] resulted in the identification of 192 genes (82 in G. hirsutum, 55 in G. arboreum, and 55 in G. raimondii). Recent study testified that modern allotetraploid Gossypium species were developed from a natural hybridization between the ancestors of two diploid species of G. raimondii (D-genome) [32] and G. arboreum (A-genome) [35] 1.7 to 1.9 million years ago [28]. The results of current study revealed a loss of quite a large number of $O M T$ genes in G. hirsutum $\mathrm{A}_{t} \mathrm{D}_{\mathrm{t}}$ genome 


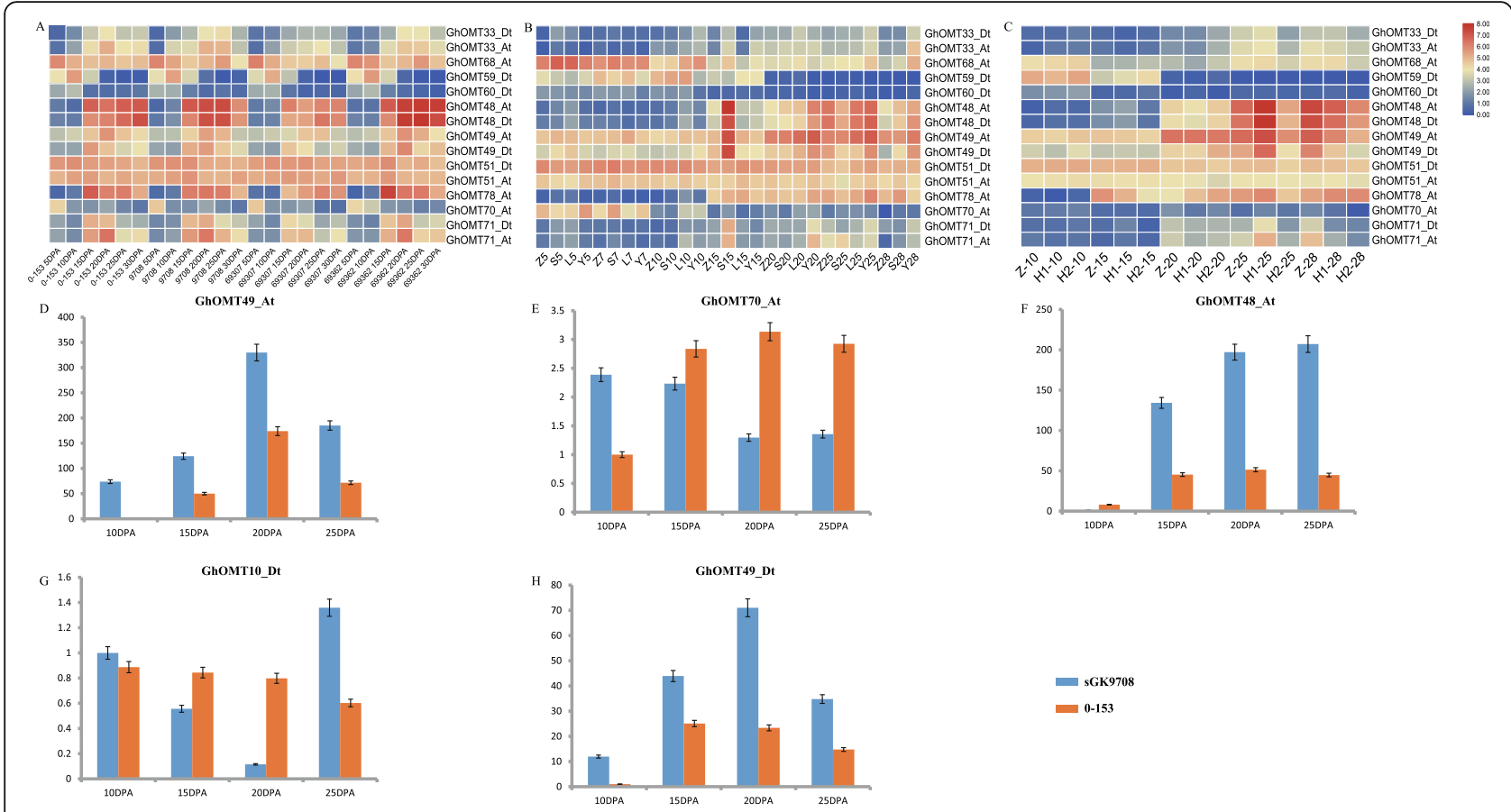

Fig. 5 Specific responses of selected OMT genes in fiber development. a Transcriptome heatmap of selected GhOMT genes in RIL lines and their parents [30]. b Transcriptome heatmap of selected GhOMT genes in CSSLs of CCRI45 and Hai1 [33, 34]; Z, S, L, and Y represent CCRI45, MBI7561, MBI7747, and MBI7285, respectively; 5, 7, 10, 15, 20, 25, and 28 represent different DPA. c Transcriptome heatmap of selected GhOMT genes in CSSLs of CCRI36 and Hai1 [29, 34]; Z, H1, and H2 represent CCRI36, MBI9915, and MBI9749; 10, 15, 20, 25, and 28 represent different DPA. d-h qRT-PCR verification results of GhOMT49_At, GhOMT70_At, GhOMT48_At, GhOMT10_Dt, GhOMT49_Dt in developing fibers of sGK9708 and 0-153 at $10,15,20$, and 25 DPAs

as compared to the total number of $O M T$ genes in A and D genomes. Possibly 19 OMT genes in $\mathrm{A}_{\mathrm{t}}$ sub-genome and 17 in $\mathrm{D}_{\mathrm{t}}$ sub-genome in G. hirsutum (Figure S1) were lost during the evolution procedure after it arose from above mentioned hybridization [28]. Gene losses can be the result of premature stop codon, disruption of genes as compared to their orthologous [37], and rapid genome re-organization during polyploidization and diploidization process [38-40]. Previous studies have evidenced that polyploidization processes may result in losing of homologous members or altered expression profiles of the homologous genes or both [31, 41-43]. Similar phenomenon was noticed in the expression profiling of homologous $O M T$ genes between $\mathrm{A}_{t}$ and $\mathrm{D}_{\mathrm{t}}$ in G. hirsutum, which clued that these genes might have experienced abovementioned events during evolution processes. Collectively, a higher number of genes were also identified in whole genome duplication event. The whole genome duplication may have resulted from an organism that inherited two genomes from each parent. Whole genome duplication events results duplicate genes that may lost through fractionation [44]. Besides the whole genome duplication, segmental duplication events were also identified with a large number in $O M T$ gene pairs. Segmental duplication is widespread in flowering plants, which might lead to the evolution of novel genes and their functions [45].
Phylogenetic analysis showed high similarity and monophyletic distribution of OMTs within Gossypium species that might support the conservative evolution mode of $O M T$ genes within five phylogenetic clades. Previous study also reported five clades of $O M T$ genes in Catalpa bungei [46]. Analyses of selection pressures revealed that most of OMT genes in Gossypium species were under a purifying selection pressure. The purifying selection pressure might suggest the importance of $O M T$ genes in Gossypium species. But noticeable exceptions were also observed in some interspecific homologous pairs, in which their $\mathrm{Ka} / \mathrm{Ks}$ values were $>1$, indicating these homologous pairs were under a positive selection pressure. These homologous pair exceptions included GrOMT52_D-GhOMT52_Scaf and GrOMT29_ D-GhOMT29_At in G. raimondii and G. hirsutum, GaOMT30_A-GhOMT30_At in G. arboreum and G. hirsutum, GrOMT63_D-GaOMT64_A and GrOMT29_DGaOMT29_A in G. raimondii and G. arboreum. These results suggested that the $O M T$ genes might had experience positive selection pressures during the evolution from diploids to tetraploids. Previous studies have evidenced that the positive selection pressure might be associated with the onsets of new functions in genes [47, 48]. Considering the fact that quite a proportion of $O M T$ genes were lost 


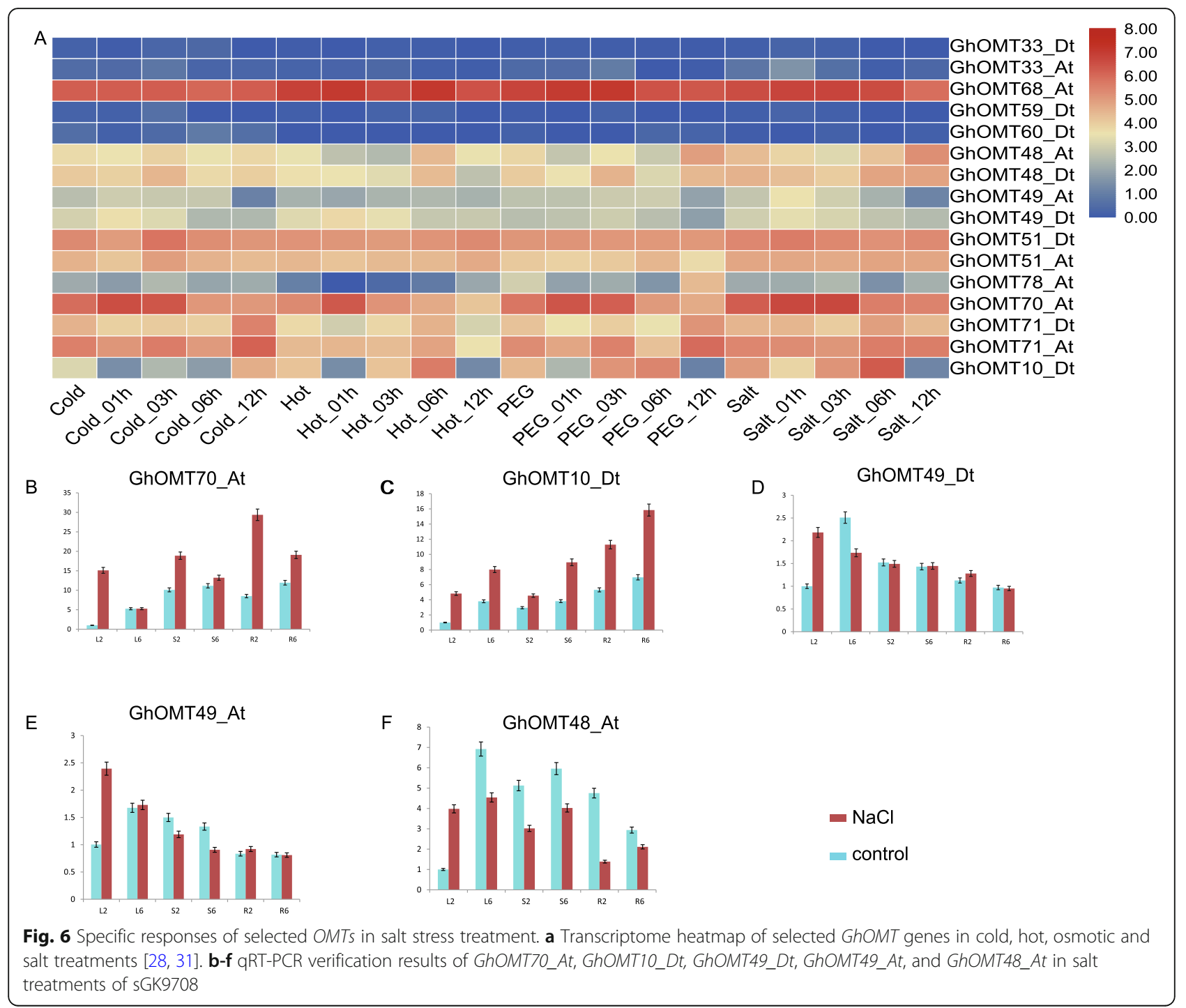

during the formation and evolution of allotetraploid cotton (see afore discussion and Figure S1). In the current study, six $O M T$ family members in G. hirsutum, one in G. arboreum and nine in G. raimondii were characterized as (R,S)-reticuline 7-O-methyltransferase. 7OMTs convert reticuline to laudanine in tetrahydrobenzylisoquinoline biosynthesis in the opium poppy Papaver somniferum, however, this enzymatic activity is unknown in most higher plants [49]. Therefore, how these genes function is still open to discussion. Taken all findings together, the results might suggest that the OMTs that experienced positive selective pressure be lost or take on some novel functions in G. hirsutum during the processes of its evolution and ancestor formation.

Previous findings have reported that the G. raimondii (D-genome) and G. arboreum (A-genome) are the closest relatives to the $D_{t}$ and $A_{t}$ sub-genomes of allotetraploids, respectively [28]. Each gene in A or D genome will always have a homolog in the correspondent $A_{t}$ or $D_{t}$ sub-genomes of G. hirsutum [50]. However, in both $\mathrm{A}$ and $\mathrm{D}$ genomes we detected quite a large number of $O M T$ genes that do not have homologs in their relative $A_{t}$ and $D_{t}$ sub-genomes (Figure S1). Previous studies evidenced that such homolog loss could result from two possible reasons: one is that the homologs were lost during the procedure of polyploidization from diploids to tetraploid; the other is that after the tetraploid formation, the OMT members in each genome started their separate evolution procedure. This separate evolution procedure makes the newly evolved members have no homologs in its relative genomes [28]. Previous studies revealed that in A, D, $A_{t} D_{t}$ genomes do not maintain same speed of evolution. A faster evolution rate was observed in allotetraploid cottons than in diploid cottons [28]. Taken the fact that 
$O M T$ genes undergo purifying selection procedures (Table S4. Sheet B), the first reason is possibly endorsed as the main cause for the current evolution status of $O M T$ gene family and the second reason may also play a role.

\section{Function prediction of OMT candidates OMTs are involved in diverse cis-regulatory elements}

Plants encounter various biotic and abiotic stresses during their entire life cycles that negatively affect growth, development, and productivity [51]. Under exposure of these stresses, plants require some potential mechanism, which can be activated in critical circumstances, to support whole plant life cycle [52]. Excessive salinity is also a major factor that affects the cotton production all around the world [53]. Identification of cis-regulatory elements revealed that the OMT genes are enriched with important cis-regulatory elements that are essential against negative environmental stresses. Some important regulatory elements, including W-box, MYB, MYC, DRE, ABRE, G-Box, MBS [54], were identified in OMT genes. W-box is important to regulate the expression of genes and to bind WRKY TFs. WRKY TFs are important to mediate plants to defense against chilling, wounding, drought, salinity and heat stresses [55-63]. MYB and MYC have been identified as involved in dehydrationresponse [64]. DRE [65], which up-regulate gene expression under cold stress and increase the tolerance of plants was also identified in these specific genes. ABRE is an important regulatory element that enhances salt stress tolerance in plants. It plays a key role in dehydration and in response to salinity stress in Arabidopsis thaliana, soybean and rice, and in response to chilling or cold in Paeonia suffruticosa [66]. G-box is identified in several gene promoters in previous studies and it contributes to development, hormone response, and tolerance against fungal infections in plants. Besides, a gibberellins response element (GARE) was also identified to be important to promote flowering in plants. The auxin hormones play a major role in growth and development of diverse plant species [67]. These results were in accordance with our findings. Especially the repetitively identified cis-regulatory elements might have biological functions in plants under specific conditions and development stages.

\section{OMTs are possibly involved in secondary metabolic pathways}

The KEGG pathways enrichment analysis revealed the involvement of OMT genes in secondary metabolism and metabolic pathways including monolignol, phenylpropanoid, flavonoid, and phenylalanine metabolisms. Secondary metabolic pathways are demonstrated to have exceptional impacts on biotic and abiotic stresses. Secondary metabolites are phytochemicals, which are synthesized through secondary metabolism. In plants, phenylpropanoids are categorized in several groups such as phenolic acids, flavonoids, and lignins, which are involved in diverse physiological processes and tolerance under unfavorable conditions [68-72]. The activity of secondary metabolites increases during the response of abiotic stresses. These phenolics provide plants with higher tolerance against heavy metals [73, 74], salinity [75], drought [76], and temperature stresses [71]. These pathways also play an important role in plant cell elongations [77, 78]. Same as, plant $O M T$ genes have been identified in secondary metabolism [79]. Higher expression of secondary metabolic pathways related genes in developing cotton fiber is reported in previous studies [80, 81]. Importantly, OMT genes were reported to be involved in lignin synthesis and to be induced by inoculation of Verticillium dahliae in cotton [82-84]. During the inoculation of pathogens, changes in the expression patterns of phenylpropanoid related OMT genes were identified. These identified OMT genes included GhOMT53_At, GhOMT58_Dt, GhOMT61_Dt, and GhOMT78_Dt that were found significantly expressed in 12 and $48 \mathrm{~h}$ post inoculation $V$. dahliae [85]. In the current study, these genes were down-regulated under abiotic stresses and in fiber development stages (Fig. 4). Previous reports have evidenced that desoxyhemigossypol-6-O-methyltransferase (dHG-6-OMT) catalyzed the biosynthesis of terpenoid and provided an effective defense mechanism to cotton plant against biotic stresses including insects and pathogens [86]. In response to $V$. dahliae (V991) in CSSLs lines CCRI36 and MBI8255, diverse genes were found differentially expressed in lignin biosynthesis including $C C O A O M T$, which can adequately utilize lignin and has been characterized in several previous studies $[87,88]$. Another study also reported that CCoAOMT was up-regulated in response to Verticillium pathogen in cotton and rendered cotton plants a comparable phenotypic resistance as compared to control plants [89]. A RNA-seq analysis based research identified differential expression patterns of $C C O A O M T$ in response to $V$. dahliae, confirming the effect of this OMT gene in the plant response to $V$. dahliae in cotton [90]. These results consequently evidenced the important role of secondary metabolic pathways and $O M T$ genes in biotic stresses in cotton.

\section{OMTs are possibly involved in plant growth, abiotic stress tolerance, and fiber development of cotton}

Salinity is one of the major causes to reduce crop yield [91] and incurs up-regulation and/or down-regulation of plant genes in response [92]. The OMT genes have been found specific for salt stress tolerance and fruit development in tomato plant (Solanum lycopersicum) [93]. The SAM-dependent methyltransferases genes were identified to play important role in sweet potato (Ipomoea batatas) in response to salt stress [94]. In wheat, TaCOMT-3D contributes to stem mechanical support [95]. Another 
TaCOMT gene was also observed with constitutive expression in stem along with leaf and root [96]. The OMT gene $(B d C O M T 1)$ was strongly expressed in stem node and internode but poorly expressed in other tissues in Brachypodium distachyon plant [97]. The expression profiles of OMT gene family in the transcriptome data of TM-1 [28] and verification results through qRT-PCR also suggested that two OMT members GhOMT10_Dt and GhOMT70_At might contribute to salt stress tolerance in G. hirsutum. In the qRT-PCR verifications, GhOMT10_Dt and GhOMT70_At showed different expression profiling from $2 \mathrm{~h}$ and $6 \mathrm{~h}$ after $200 \mathrm{mM} \mathrm{NaCl}$ treatment (Fig. 5). Probably they act differently in response to salt stress in G. hirsutum. Five genes including GhOMT1_At, GhOMT41_At, GhOMT47_At, GhOMT17_Dt, and GhOMT37_Dt had significant expressions in stem (Fig. 4a) where they might be the potential candidates to provide structural support and survival to plant in environmental stresses.

Cotton fiber quality of is an important attribute to develop elite cultivars in the presence of negative environmental factors. Studies demonstrated that GhOMT48_At and GhOMT49_At were expressed at elongation stages of a CSSL (CS-B25) and TM-1 respectively [28, 98]. In the current study, the fiber specific OMT genes were consistently identified across various populations and species including TM-1 (Fig. 4a) G. arboreum (Fig. 4b) G. raimondii (Fig. 4c), RILs (Fig. 5a), CSSLs (Fig. 5b, c). They also showed highly similar expression patterns in different fiber development stages. The expression specificities of GhOMT48_At, GhOMT49_At, and GhOMT49_Dt in developing fibers were further verified through qRT-PCR studies (Fig. 5d, f and h). The results demonstrated that these $O M T$ members could have a significant function in fiber development and fiber quality formation. But how these genes function during fiber quality formation was still open to discussion.

Lignins-like phenolics are widely studied in response to stress [99]. Recent research advancements revealed that lignin or phenolics influence fiber development at elongation and secondary cell wall synthesis stages [100]. The knock-down of Lignin-like phenolics related gene (GhbHLH18) in G. hirsutum evidenced the regulation of lignin-like phenolics pathway genes including a COMT and others, during cotton fiber elongation and secondary cell wall synthesis stages. The results demonstrated the roles of these genes in regulating the lignification in developing cotton fibers [7]. This study has gathered important information of $O M T$ gene family which is a forward step in research to uncover the possible functions or to support previous studies in exploration the functions of $O M T$ genes in plant response to salt stress and in cotton fiber development.

\section{Conclusions}

Methyltransferases are versatile class of enzymes. OMT contributes to diverse phenolics that are essential for plant growth and serves as protective shield against several kinds of stresses. Various bioinformatics analyses revealed that $O M T$ gene family is a strong growth regulator, which not only provide protection to the plant, but also are involved in fiber elongation and secondary cell wall synthesis stages. Furthermore, expression profiling analysis based on several transcriptome data and qRT-PCR validation inferred that GhOMT10_ Dt and GhOMT70_At might be the potential candidates for salt stress tolerance and that GhOMT48_At, GhOMT49_At, and GhOMT49_Dt might have significant influence in fiber development at elongation and secondary cell wall thickness stages of G. hirsutum. This proposed study concludes the important roles of OMT family genes in cotton fiber development and in salt stress tolerance.

\section{Methods}

Identification of OMT protein family members, sequences alignment, and phylogenetic tree construction

Genome data of three Gossypium species including G. arboreum (CRI), G. raimondii (JGI), and G. hirsutum (NAU) were downloaded from cotton functional genomic database (https://cottonfgd.org/) [101]. Genome data of $A$. thaliana (Athaliana/TAIR10, https://genome.jgi.doe.gov/portal/pages/ dynamicOrganismDownload.jsf?organism=Athaliana\#) [102] and T. cacao (Tcacao/v2.1, https://genome.jgi.doe.gov/portal/ pages/dynamicOrganismDownload.jsf?organism=Tcacao\#) [103] were also downloaded for comparative analysis of OMT genes. The hidden Markov model profiles (PF00891 and PF01596) were downloaded from Pfam database (https:// pfam.xfam.org/). The hmmsearch program of HMMER 3.0 software [104] was used to search for protein sequences of three Gossypium species with the E-value of $1 \mathrm{e}-5$. OMT protein sequences of $A$. thaliana and T. cacao were also retrieved from the Phytozome database (https://phytozome.jgi.doe.gov/ pz/portal.html) for phylogenetic analysis. The proteins with absence of required domains were manually removed. Other features of OMT genes including protein length (aa), and molecular weight $(\mathrm{kDa})$ were characterized by using cotton functional genomic database (http://www.cottonfgd.org/) [101]. The full length amino acid sequences of G. hirsutum, G. arboreum, G. raimondii, A. thaliana, and T. cacao encoded by OMT genes were aligned with clustalx2 software (http:// www.clustal.org/) [105] with default parameters for the neighbor-joining phylogenetic tree as 1000 bootstraps. Subsequently, two neighbor-joining phylogenetic trees were generated by using Mega7 [106]. The topology of both phylogenetic trees was confirmed to understand the phylogenic relationship within the five plant species. 
Nomenclature of these members was based on their chromosomal locations, homology and numbers in each Gossypium species.

\section{Chromosomal mapping and collinearity analysis}

TBtools was used to perform the chromosomal mapping of the given $O M T$ genes, to search the homologous pairs of OMT genes between genomes of the three Gossypium species through protein-protein blast (E-value le-5). Circle gene viewer model of TBtools software was used to visualize the results of collinearity between homologous gene pairs [16].

\section{Gene structure and conserved motifs}

The structure of the OMT genes was analyzed using the online server of Gene Structure Display (GSDS 2.0, http://gsds.cbi.pku.edu.cn) [107]. The conserved motifs were predicted online in MEME web based motif prediction tool version 5.0 .5 (http://meme-suite.org/) by providing protein sequences of $O M T$ genes [108].

\section{Selection pressure, cis-regulatory elements, sub-cellular localization and gene enrichment analysis}

The CDS of homologous gene pairs of G. hirsutum (NAU), G. arboreum (CRI), and G. raimondii (JGI) were assigned to TBtools software to estimate the $\mathrm{Ka} / \mathrm{Ks}$ ratio to predict selection pressure between the genes of each pair in genomes and sub-genomes [16]. The upstream sequences $(2000 \mathrm{bp})$ of $O M T$ genes were retrieved through cotton functional genomic database (http:// www.cottonfgd.org) and were submitted to PlantCARE database [109] to obtain the cis-regulatory elements. Sub-cellular localization of genes was predicted using online bioinformatics tools CELLO v.2.5 and Wolf Psort with their protein sequences $[24,110]$. KEGG IDs of $O M T$ family genes were downloaded from cotton functional genomic database (http://www.cottonfgd.org), then annotation was performed by providing KEGG IDs in kyoto encyclopedia of genes and genomes database (https://www.genome.jp/kegg/) [111]. Gene ontology (GO) annotation IDs of OMT family genes were downloaded from cotton functional genomic database (http://www.cottonfgd.org) and were submitted to Gene ontology database (http://geneontology.org/) to perform GO analysis [112].

\section{Expression profiling of OMT genes}

The different sets of RNA sequencing data including TM1, a genetic standard line of G. hirsutum (Nanjing Agricultural University, Nanjing, Jiangsu, China) (PRJNA248163) [28, 31], 69,307 and 69,362 (selected lines from a RIL population sGK9708 $\times 0-153$, Institute of Cotton Research, Anyang, Henan, China) (PRJNA542946) [30], MBI7747, MBI7561, and MBI7285 (selected lines from
CSSL population CCRI45 $\times$ Hail，SRP084203) [33, 34], and MBI9915 and MBI9749 (selected lines from CSSL population CCRI36 $\times$ Hai1, SRX2843778) (Institute of Cotton Research, Anyang, Henan, China) [29, 34] were included in this study to observe the expression pattern of $O M T$ family genes at different growth stages, under abiotic stress treatment stages, ovule development, and in different fiber development stages of cotton. Briefly, 69,307, 0-153, MBI7747, MBI7561, MBI9915, MBI9749, and Hail have high fiber quality traits, while 69,362, MBI7285, sGK9708, CCRI36, and CCRI45 have low fiber quality traits. Detailed information of these referenced materials is presented in Table S1.

Transcriptome data of G. arboreum (PRJNA179447) [35], and G. raimondii (PRJNA79005) [32] were also included to compare the comparative expression of these $O M T$ genes.

\section{Plant material, RNA isolation, CDNA synthesis, and qRT- PCR}

Upland cotton cultivar $0-153$ had elite fiber quality while sGK9708 had high yield potential and wide adaptability. They are successfully used to tag fiber quality and yield QTLs in our previous reports [30, 113, 114]. In the current study, sGK9708 and 0-153 (Table S1) were planted in April 2018 in the experimental fields of the Institute of Cotton Research, Chinese Academy of Agricultural Sciences, Anyang, Henan. Flowers were tagged on the day of anthesis for fiber sampling in July 2018. Bolls of tagged flowers were sampled in the morning between 9:00 and 10:00 AM at 10,15, 20, and 25 days' post anthesis (DPA). The fibers were dissected from the developing seeds right after boll picking and immediately stored at $-80^{\circ} \mathrm{C}$ for RNA extraction.

To examine the expression profiling of OMT genes under salt stress, seeds of sGK9708 cultivar were germinated in wet filter papers for $72 \mathrm{~h}$ and then were transferred to hydroponic conditions. The seedlings were treated with $200 \mathrm{mM} \mathrm{NaCl}$ at three leaves stage. The true leaves, stems, and roots were sampled at $0 \mathrm{~h}, 2 \mathrm{~h}$, and $6 \mathrm{~h}$ of the treatment. The $0 \mathrm{~h}$ of treatment was considered as control sample to compare the expression profiling with treated samples.

Total RNA isolation was performed with the RNAprep Pure Plant Kit by (Tiangen, Beijing, China). To eliminate the genomic DNA contamination, the RNA samples were treated with DNase1. RNA concentration and integrity was observed on Nano Drop 2000 spectrophotometer (Thermo scientific, USA) and 1\% agarose gel electrophoresis. cDNAs of the RNA samples that the A260/280 ratio reached 2.00 were synthesized using PrimeScript $^{\circ}$ RT Reagent Kit (Perfect Real Time, Takara Biotechnology Co., Ltd., Dalian, China). qRT-PCR was performed with ABI 7500 fast Real-Time PCR system 
(Applied Biosystems, USA), with Gh-Histone3 gene was used as reference to normalize the relative expression level. Primers pairs of five $O M T$ genes were designed by using Oligo 7 [115] (Table S2). $2^{-\Delta \Delta} \mathrm{Ct}$ method was used to calculate the gene expressions [116].

\section{Supplementary Information}

The online version contains supplementary material available at https://doi. org/10.1186/s12870-020-02786-6.

Additional file 1: Figure S1. Chromosomal distribution of OMT genes in the genomes of Gossypium species. a: in D genome ( $G$. raimondii), b: in A genome ( $G$. arboreum), c:in $A_{t} D_{t}$ genomes (G. hirsutum), d: in scaffolds of the three genomes. The genes in boxes in $A$ and $D$ genomes represent that their homologous genes in $A_{t}$ and $D_{t}$ sub-genomes are missing, while the genes in boxes in At and Dt sub-genomes represent that their homologous genes in A and D genomes are missing.

Additional file 2: Figure S2. Identification of motifs of OMT genes in three Gossypium species.

Additional file 3: Figure S3. Identification of cis-regulatory elements of OMT genes.

Additional file 4: Table S1. Detail Information of plant materials used for RNA-seq data acquisition.

Additional file 5: Table S2. Sequences of Primer Pairs of five selected OMT family genes for $\mathrm{QRT}$-PCR verification.

Additional file 6: Table S3. Basic information and analyses of OMT genes in Gossypium species (Sheet A), and in A. thaliana and T. cacao (Sheet B).

Additional file 7: Table S4. Analyses of duplication events and selection pressure. Sheet A: The analysis of duplication events of OMT genes in A genome (G. arboreum), D genome (G. raimondii), and $A_{t} D_{t}$ genomes (G. hirsutum). Sheet B: The comparative analysis of selection pressure $(\mathrm{Ka} / \mathrm{Ks})$ of OMT genes in G. raimondii, G. arboreum, and G. hirsutum.

Additional file 8: Table S5. Structural features of OMT genes.

\section{Abbreviations}

aa: amino acid; DPA: Days post anthesis; CCOAOMT: Caffeoyl coenzyme A 3O-methyltransferase; CMTs: C-methyltransferases; COMTs: Caffeic acid 3-Omethyltransferases; NMTs: N-methyltransferases; OMT: O-methyltransferase; kDa: kilodalton; GO: Gene ontology; KEGG: Kyoto encyclopedia of genes and genomes; Ka: the number of non-synonymous substitutions per nonsynonymous site; Ks: the number of synonymous substitutions per synonymous site; CSSLs: Chromosome segment substitution lines; RILs: Recombinant inbred lines; SAM: S-adenosyl-I-methionine; Ga: Gossypium arboreum; Gh: Gossypium hirsutum; Gr: Gossypium raimondii; qRTPCR: quantitative real-time polymerase chain reaction

\section{Acknowledgements}

The authors acknowledge SciLang for its linguistic assistance during the preparation of this manuscript and the anonymous reviewers for their valuable comments and helpful suggestions which help to improve the manuscript.

\section{Authors' contributions}

$\mathrm{AH}$ and WG designed the project, QG, QZ, MSI and XD performed the formal analysis, JL, JG, YS, HS, RL, ÀL and AR provide the methodology, QZ and QG performed the software, $Y Y$ and $W G$ supervised the study, AH and WG drafted the manuscript, MA, YY and WG reviewed \& edited the manuscript. All authors have read and approved the manuscript.

\section{Funding}

This research was funded by the National Key R\&D Program of China (2017YFD0101603, 2016YFD0101401, 2016YFD0100500), the Natural Science Foundation of China (31471538 and 31371668), the Agricultural Science and Technology Innovation Program for CAAS (CAAS-ASTIP-ICRCAAS), the
National High Technology Research and Development Program of China (2012AA101108 and 2009AA101104) and the Central Level of the Scientific Research Institutes for Basic R \& D Special Fund Business (1610162014008). The funding agencies provided only the expenses and fees of this study. The experimental design and collection, analysis, and interpretation of data and manuscript writing were performed by the contributing authors.

\section{Availability of data and materials}

All data generated or analyzed during this study are included in this published article and its supplementary information files.

\section{Ethics approval and consent to participate}

Not applicable.

\section{Consent for publication}

Not applicable.

\section{Competing interests}

Authors declare that they have no competing interests for the publication of the manuscript

Received: 17 June 2020 Accepted: 7 December 2020 Published online: 11 January 2021

\section{References}

1. Lee JJ, Woodward AW, Chen ZJ. Gene expression changes and early events in cotton fibre development. Ann Bot. 2007;100(7):1391-401.

2. Angelini LG, Lazzeri A, Levita G, Fontanelli D, Bozzi C. Ramie (Boehmeria nivea (L.) gaud.) and Spanish broom (Spartium junceum L.) fibres for composite materials: agronomical aspects, morphology and mechanical properties. Ind Crop Prod. 2000;11(2-3):145-61.

3. Day A, Ruel K, Neutelings G, Cronier D, David H, Hawkins S, Chabbert B. Lignification in the flax stem: evidence for an unusual lignin in bast fibers. Planta. 2005;222(2):234-45.

4. Zhang SY, Jia TT, Zhang Z, Zou XY, Fan SM, Lei K, Jiang X, Niu DD, Yuan YL, Shang $\mathrm{HH}$. Insight into the relationship between S-lignin and fiber quality based on multiple research methods. Plant Physiol Biochem. 2020;147:251-61.

5. Liu CJ. Deciphering the enigma of lignification: precursor transport, oxidation, and the topochemistry of lignin assembly. Mol Plant. 2012;5(2): 304-17.

6. Fan L, Shi WJ, Hu WR, Hao XY, Wang DM, Yuan H, Yan HY. Molecular and biochemical evidence for phenylpropanoid synthesis and presence of walllinked phenolics in cotton fibers. J Integr Plant Biol. 2009:51(7):626-37.

7. Gao Z, Sun W, Wang J, Zhao C, Zuo K. GhbHLH18 negatively regulates fiber strength and length by enhancing lignin biosynthesis in cotton fibers. Plant Sci. 2019;286:7-16

8. Boerjan W, Ralph J, Baucher M. Lignin biosynthesis. Annu Rev Plant Biol. 2003;54(1):519-46.

9. Zhong RM, Negrel WH, Ye J, Zheng-Hua. Dual methylation pathways in lignin biosynthesis. Plant Cell. 1998;10(12):2033-45.

10. Ye ZH, Varner JE. Differential expression of two O-methyltransferases in lignin biosynthesis in Zinnia elegans. Plant Physiol. 1995;108(2):459-67.

11. Bugos RC, Chiang VL, Campbell WH. CDNA cloning, sequence analysis and seasonal expression of lignin-bispecific caffeic acid/5-hydroxyferulic acid Omethyltransferase of aspen. Plant Mol Biol. 1991;17(6):1203-15.

12. Vincent D, Lapierre C, Pollet B, Cornic G, Negroni L, Zivy M. Water deficits affect caffeate O-methyltransferase, lignification, and related enzymes in maize leaves. A proteomic investigation. Plant Physiol. 2005:137(3):949-60.

13. Zubieta C, Kota P, Ferrer JL, Dixon RA, Noel JP. Structural basis for the modulation of lignin monomer methylation by caffeic acid/5-hydroxyferulic acid 3/5-O-methyltransferase. Plant Cell. 2002;14(6):1265-77.

14. Li JJ, Zhang G, Yu JH, Li YY, Huang XH, Wang WJ, Tan R, Zhou JY, Liao H. Molecular cloning and characterization of caffeic acid 3-O-methyltransferase from the rhizome of Ligusticum chuanxiong. Biotechnol Lett. 2015;37(11):2295-302.

15. Ma J, Liu F, Wang Q, Wang K, Jones DC, Zhang B. Comprehensive analysis of TCP transcription factors and their expression during cotton (Gossypium arboreum) fiber early development. Sci Rep. 2016;6:1-10.

16. Chen C, Chen H, Zhang Y, Thomas HR, Frank MH, He Y, Xia R. TBtools-an integrative toolkit developed for interactive analyses of big biological data. Mol Plant. 2020;13(8):1194-202. 
17. Qiao X, Li Q, Yin H, Qi K, Li L, Wang R, Zhang S, Paterson AH. Gene duplication and evolution in recurring polyploidization-diploidization cycles in plants. Genome Biol. 2019;20(1):38.

18. Hurst LD. The Ka/Ks ratio: diagnosing the form of sequence evolution. Trends Genet. 2002;9(18):486-7.

19. Ma W, Zhao T, Li J, Liu B, Fang L, Hu Y, Zhang T. Identification and characterization of the GhHsp20 gene family in Gossypium hirsutum. Sci Rep. 2016;6:1-13.

20. Kim J, Choi B, Cho B-K, Lim H-S, Kim JB, Natarajan S, Kwak E, Bae H. Molecular cloning, characterization and expression of the caffeic acid Omethyltransferase (COMT) ortholog from kenaf (Hibiscus cannabinus). Plant Omics. 2013;6(4):246-53.

21. Binder JX, Pletscher-Frankild S, Tsafou K, Stolte C, O'Donoghue SI, Schneider $R$, Jensen L. COMPARTMENTS: unification and visualization of protein subcellular localization evidence. Database. 2014;2014:12

22. Herold N, Will CL, Wolf E, Kastner B, Urlaub H, Lührmann R. Conservation of the protein composition and electron microscopy structure of Drosophila melanogaster and human spliceosomal complexes. Mol Cell Biol. 2009;29(1): 281-301.

23. Andersen JS, Lyon CE, Fox AH, Leung AK, Lam YW, Steen H, Mann M, Lamond Al. Directed proteomic analysis of the human nucleolus. Curr Biol. 2002;12(1):1-11.

24. Horton P, Park K-J, Obayashi T, Fujita N, Harada H, Adams-Collier C, Nakai K. WoLF PSORT: protein localization predictor. Nucleic Acid Res. 2007;35(suppl_ 2):W585-7.

25. Briesemeister S, Rahnenführer J, Kohlbacher O. Going from where to why -interpretable prediction of protein subcellular localization. Bioinformatics. 2010;26(9):1232-8.

26. Pierleoni A, Martelli PL, Fariselli P, Casadio R. BaCelLo: a balanced subcellular localization predictor. Bioinformatics. 2006;22(14):e408-16.

27. Goldberg T, Hamp T, Rost B. LocTree2 predicts localization for all domains of life. Bioinformatics. 2012;28(18):i458-65.

28. Hu Y, Chen J, Fang L, Zhang Z, Ma W, Niu Y, Ju L, Deng J, Zhao T, Lian J. Gossypium barbadense and Gossypium hirsutum genomes provide insights into the origin and evolution of allotetraploid cotton. Nat Genet. 2019;51(4): 739-48.

29. Li P-T, Wang M, Lu Q-W, Ge Q, Liu A-Y, Gong J-W, Shang H-H, Gong W-K, Li J-W, Song W-W. Comparative transcriptome analysis of cotton fiber development of Upland cotton (Gossypium hirsutum) and Chromosome Segment Substitution Lines from G. hirsutum× G. barbadense. BMC Genom. 2017;18(1):705.

30. Zhang Z, Li J, Jamshed M, Shi Y, Liu A, Gong J, Wang S, Zhang J, Sun F, Jia $F$, et al. Genome-wide quantitative trait loci reveal the genetic basis of cotton fibre quality and yield-related traits in a Gossypium hirsutum recombinant inbred line population. Plant Biotechnol J. 2020;18(1):239-53.

31. Zhang T, Hu Y, Jiang W, Fang L, Guan X, Chen J, Zhang J, Saski CA, Scheffler BE, Stelly DM, et al. Sequencing of allotetraploid cotton (Gossypium hirsutum L. acc. TM-1) provides a resource for fiber improvement. Nat Biotechnol. 2015:33(5):531-7.

32. Wang K, Wang Z, Li F, Ye W, Wang J, Song G, Yue Z, Cong L, Shang H, Zhu $\mathrm{S}$. The draft genome of a diploid cotton Gossypium raimondii. Nat Genet. 2012;44(10):1098-103.

33. Lu Q, Shi Y, Xiao X, Li P, Gong J, Gong W, Liu A, Shang H, Li J, Ge Q, et al. Transcriptome Analysis Suggests That Chromosome Introgression Fragments from Sea Island Cotton (Gossypium barbadense) Increase Fiber Strength in Upland Cotton (Gossypium hirsutum). G3 (Bethesda). 2017;7(10):3469-79.

34. Shi Y, Li W, Li A, Ge R, Zhang B, Li J, Liu G, Li J, Liu A, Shang H. Constructing a high-density linkage map for Gossypium hirsutum× Gossypium barbadense and identifying QTLs for lint percentage. J Integr Plant Biol. 2015;57(5):450-67.

35. Du X, Huang G, He S, Yang Z, Sun G, Ma X, Li N, Zhang X, Sun J, Liu M, et al. Resequencing of 243 diploid cotton accessions based on an updated a genome identifies the genetic basis of key agronomic traits. Nat Genet. 2018;50(6):796-802.

36. Paterson AH, Wendel JF, Gundlach H, Guo H, Jenkins J, Jin D, Llewellyn D, Showmaker KC, Shu S, Udall J, et al. Repeated polyploidization of Gossypium genomes and the evolution of spinnable cotton fibres. Nature. 2012:492(7429):423-7.

37. Gan X, Stegle O, Behr J, Steffen JG, Drewe P, Hildebrand KL, Lyngsoe R, Schultheiss SJ, Osborne EJ, Sreedharan VT, et al. Multiple reference genomes and transcriptomes for Arabidopsis thaliana. Nature. 2011;477(7365):419-23.
38. Brenchley R, Spannagl M, Pfeifer M, Barker GL, D'Amore R, Allen AM McKenzie N, Kramer M, Kerhornou A, Bolser D. Analysis of the bread wheat genome using whole-genome shotgun sequencing. Nature. 2012;491(7426): 705-10.

39. Otto SP. The evolutionary consequences of polyploidy. Cell. 2007;131(3): $452-62$.

40. Soltis PS, Soltis DE. The role of hybridization in plant speciation. Annu Rev Plant Biol. 2009:60:561-88.

41. Grover CE, Gallagher JP, Szadkowski EP, Yoo MJ, Flagel LE, Wendel JF. Homoeolog expression bias and expression level dominance in allopolyploids. New Phytol. 2012;196(4):966-71.

42. Leach LJ, Belfield EJ, Jiang C, Brown C, Mithani A, Harberd NP. Patterns of homoeologous gene expression shown by RNA sequencing in hexaploid bread wheat. BMC Genomics. 2014;15(1):276.

43. Cheng F, Wu J, Fang L, Sun S, Liu B, Lin K, Bonnema G, Wang X. Biased gene fractionation and dominant gene expression among the subgenomes of Brassica rapa. PLoS One. 2012;7(5):e36442.

44. Cheng F, Wu J, Cai X, Liang J, Freeling M, Wang X. Gene retention, fractionation and subgenome differences in polyploid plants. Nature plants. 2018:4(5):258-68.

45. Renny-Byfield S, Gallagher JP, Grover CE, Szadkowski E, Page JT, Udall JA, Wang X, Paterson AH, Wendel JF. Ancient gene duplicates in Gossypium (cotton) exhibit near-complete expression divergence. Genome Biology and Evolution. 2014;6(3):559-71.

46. Lu N, Ma W, Han D, Liu Y, Wang Z, Wang N, Yang G, Qu G, Wang Q, Zhao K. Genome-wide analysis of the Catalpa bungei caffeic acid Omethyltransferase (COMT) gene family: identification and expression profiles in normal, tension, and opposite wood. PeerJ. 2019;7:e6520.

47. Van Zee JP, Schlueter JA, Schlueter S, Dixon P, Sierra CAB, Hill CA. Paralog analyses reveal gene duplication events and genes under positive selection in Ixodes scapularis and other ixodid ticks. BMC Genomics. 2016;17(1):241.

48. Conant GC, Wolfe KH. Turning a hobby into a job: how duplicated genes find new functions. Nat Rev Genet. 2008;9(12):938-50.

49. Ounaroon A, Decker G, Schmidt J, Lottspeich F. Kutchan TM: (R, S)-Reticuline 7O-methyltransferase and (R, S)-norcoclaurine 6-O-methyltransferase of Papaver somniferum-cDNA cloning and characterization of methyl transfer enzymes of alkaloid biosynthesis in opium poppy. Plant J. 2003;36(6):808-19.

50. Ge Q, Cui Y, Li J, Gong J, Lu Q, Li P, Shi Y, Shang H, Liu A, Deng X, et al. Disequilibrium evolution of the Fructose-1, 6-bisphosphatase gene family leads to their functional biodiversity in Gossypium species. BMC Genomics. 2020:21:379.

51. Lamaoui M, Jemo M, Datla R, Bekkaoui F. Heat and drought stresses in crops and approaches for their mitigation. Front Chem. 2018;6:26.

52. Rao KM, Raghavendra A, Reddy KJ. Physiology and molecular biology of stress tolerance in plants. Dordrecht: Springer Science \& Business Media; 2006

53. Xu P, Liu Z, Fan X, Gao J, Zhang X, Zhang X, Shen X. De novo transcriptome sequencing and comparative analysis of differentially expressed genes in Gossypium aridum under salt stress. Gene. 2013;525(1):26-34.

54. Sazegari S, Niazi A, Ahmadi FS. A study on the regulatory network with promoter analysis for Arabidopsis DREB-genes. Bioinformation. 2015;11(2): 101-6.

55. Meier S, Bastian R, Donaldson L, Murray S, Bajic V, Gehring C. Co-expression and promoter content analyses assign a role in biotic and abiotic stress responses to plant natriuretic peptides. BMC Plant Biol. 2008;8(1):24.

56. Maleck K, Levine A, Eulgem T, Morgan A, Schmidl J, Lawton K, Dangl J, Dietrich R. An Arabidopsis promoter element shared among genes co-regulated during systemic acquired disease resistance. Nat Genet. 2000;26:403-10.

57. Eulgem T, Rushton PJ, Robatzek S, Somssich IE. The WRKY superfamily of plant transcription factors. Trends Plant Sci. 2000;5(5):199-206.

58. Huang T, Nicodemus J, Zarka DG, Thomashow MF, Wisniewski M, Duman JG. Expression of an insect (Dendroides canadensis) antifreeze protein in Arabidopsis thaliana results in a decrease in plant freezing temperature. Plant Mol Biol. 2002;50(3):333-44.

59. Hara K, Yagi M, Kusano T, Sano H. Rapid systemic accumulation of transcripts encoding a tobacco WRKY transcription factor upon wounding Mol Gen Genet. 2000;263(1):30-7.

60. Rizhsky L, Davletova S, Liang H, Mittler R. The zinc finger protein Zat12 is required for cytosolic ascorbate peroxidase 1 expression during oxidative stress in Arabidopsis. J Biol Chem. 2004;279(12):11736-43.

61. Pnueli L, Hallak-Herr E, Rozenberg M, Cohen M, Goloubinoff P, Kaplan A, Mittler R. Molecular and biochemical mechanisms associated with 
dormancy and drought tolerance in the desert legume Retama raetam. Plant J. 2002;31(3):319-30.

62. Seki M, Ishida J, Narusaka M, Fujita M, Nanjo T, Umezawa T, Kamiya A, Nakajima M, Enju A, Sakurai T. Monitoring the expression pattern of around 7,000 Arabidopsis genes under ABA treatments using a full-length cDNA microarray. Function Integr Genom. 2002;2(6):282-91.

63. Rizhsky L, Liang H, Shuman J, Shulaev V, Davletova S, Mittler R. When defense pathways collide. The response of Arabidopsis to a combination of drought and heat stress. Plant Physiol. 2004;134(4):1683-96.

64. Abe H, YamaguchiShinozaki K, Urao T, Iwasaki T, Hosokawa D, Shinozaki K. Role of Arabidopsis MYC and MYB homologs in drought- and abscisic acidregulated gene expression. Plant Cell. 1997;9(10):1859-68.

65. Thomashow MF. Molecular basis of plant cold acclimation: insights gained from studying the CBF cold response pathway. Plant Physiol. 2010;154(2):571-7.

66. Zhang Y, Sun T, Liu S, Dong L, Liu C, Song W, Liu J, Gai S. MYC cis-elements in PSMPT promoter is involved in chilling response of Paeonia suffruticosa. PLoS One. 2016;11(5):e0155780.

67. Zhao Y. Auxin biosynthesis and its role in plant development. Annu Rev Plant Biol. 2010;61:49-64.

68. Ramawat KG, Mérillon J-M. Natural products: phytochemistry, botany and metabolism of alkaloids, phenolics and terpenes. Heidelberg: Springer; 2013.

69. Cheynier V, Comte G, Davies KM, Lattanzio V, Martens S. Plant phenolics: recent advances on their biosynthesis, genetics, and ecophysiology. Plant Physiol Biochem. 2013;72:1-20.

70. de la Rosa LA, Alvarez-Parrilla E and Gonzalez-Aguilar GA. Fruit and Vegetable Phytochemicals: Chemistry, Nutritional Value and Stability. Ames: Wiley; 2009.

71. Naikoo MI, Dar Ml, Raghib F, Jaleel H, Ahmad B, Raina A, Khan FA, Naushin F. Role and regulation of plants Phenolics in abiotic stress tolerance: an overview. In: Plant Signaling Molecules. Elsevier; 2019. p. 157-68.

72. Dixon RAP, N. L. Stress-induced Phenylpropanoid metabolism. Plant Cell. 1995:7(7):1085-97.

73. Handa N, Kohli SK, Sharma A, Thukral AK, Bhardwaj R, Abd Allah EF, Alqarawi AA, Ahmad P. Selenium modulates dynamics of antioxidative defence expression, photosynthetic attributes and secondary metabolites to mitigate chromium toxicity in Brassica juncea L. plants. Environ Exp Bot. 2019;161:180-92

74. Smirnov OE, Kosyan AM, Kosyk OI, Taran NY. Response of phenolic metabolism induced by Aluminium toxicity in Fagopyrum Esculentum Moench. Plants. Ukrainian Biochem J. 2015:87(6):129-35.

75. Weretilnyk EA, Alexander KJ, Drebenstedt M, Snider JD, Summers PS, Moffatt BA. Maintaining methylation activities during salt stress. The involvement of adenosine kinase. Plant Physiol. 2001;125(2):856-65.

76. Ancillotti C, Bogani P, Biricolti S, Calistri E, Checchini L, Ciofi L, Gonnelli C, Del Bubba M. Changes in polyphenol and sugar concentrations in wild type and genetically modified Nicotiana langsdorffii Weinmann in response to water and heat stress. Plant Physiol Biochem. 2015;97:52-61.

77. Sasayama D, Azuma T, Itoh K. Involvement of cell wall-bound phenolic acids in decrease in cell wall susceptibility to expansins during the cessation of rapid growth in internodes of floating rice. J Plant Physiol. 2011; 168(2):121-7.

78. Fan L, Linker R, Gepstein S, Tanimoto E, Yamamoto R, Neumann PM. Progressive inhibition by water deficit of cell wall extensibility and growth along the elongation zone of maize roots is related to increased lignin metabolism and progressive stelar accumulation of wall phenolics. Plant Physiol. 2006;140(2):603-12

79. Wang J, Pichersky E. Identification of specific residues involved in substrate discrimination in two plant O-methyltransferases. Archiv Biochem Biophys. 1999;368(1):172-80.

80. Gou JY, Wang $\amalg$, Chen SP, Hu WL, Chen XY. Gene expression and metabolite profiles of cotton fiber during cell elongation and secondary cell wall synthesis. Cell Res. 2007;17(5):422-34.

81. Al-Ghazi Y, Bourot S, Arioli T, Dennis ES, Llewellyn DJ. Transcript profiling during fiber development identifies pathways in secondary metabolism and cell wall structure that may contribute to cotton fiber quality. Plant Cell Physiol. 2009;50(7):1364-81.

82. Grimmig B, Kneusel $R$, Junghanns K, Matern U. Expression of Bifunctional Caffeoyl-CoA 3-O-methyltransferase in stress compensation and lignification. Plant Biol. 1999;1(3):299-310.

83. Ni W, Fahrendorf T, Ballance GM, Lamb CJ, Dixon RA. Stress responses in alfalfa (Medicago sativa L.). XX. Transcriptional activation of phenylpropanoid pathway genes in elicitor-induced cell suspension cultures. Plant Mol Biol. 1996;30(3):427-38.

84. Cui Y, BELL AA, Joost O, Magill C. Expression of potential defense response genes in cotton. Physiol Mol Plant Pathol. 2000;56(1):25-31.

85. Li C, He Q, Zhang F, Yu J, Li C, Zhao T, Zhang Y, Xie Q, Su B, Mei L. Melatonin enhances cotton immunity to Verticillium wilt via manipulating lignin and gossypol biosynthesis. Plant J. 2019;100(4):784-800.

86. Liu J, Benedict CR, Stipanovic RD, Bell AA. Purification and characterization ofS-Adenosyl-I-methionine: desoxyhemigossypol-6-O-methyltransferase from cotton plants. An enzyme capable of methylating the defense terpenoids of cotton. Plant Physiol. 1999;121(3):1017-24.

87. Wang W, Li R, Zhu Q, Tang X, Zhao Q. Transcriptomic and physiological analysis of common duckweed Lemna minor responses to $\mathrm{NH} 4+$ toxicity. BMC Plant Biol. 2016;16(1):92

88. P-t L, T-t C, Lu Q-W, Ge Q, Gong W-K, Liu A-Y, Gong J-W, Shang H-H, Deng $X-Y, L i ~ J-W$. Transcriptomic and biochemical analysis of upland cotton (Gossypium hirsutum) and a chromosome segment substitution line from G. hirsutum $\times$ G. barbadense in response to Verticillium dahliae infection. BMC Plant Biol. 2019;19(1):1-24.

89. Tang Y, Zhang ZN, Lei Y, Hu G, Liu JF, Hao MY, Chen AM, Peng QZ, Wu JH. Cotton WATs modulate SA biosynthesis and local lignin deposition participating in plant resistance against Verticillium dahliae. Front Plant Sci. 2019;10:526.

90. Xu L, Zhu L, Tu L, Liu L, Yuan D, Jin L, Long L, Zhang X. Lignin metabolism has a central role in the resistance of cotton to the wilt fungus Verticillium dahliae as revealed by RNA-Seq-dependent transcriptional analysis and histochemistry. J Exp Bot. 2011;62(15):5607-21.

91. Tuteja N. Mechanisms of high salinity tolerance in plants. Methods Enzymol. 2007:428:419-38.

92. Joshi A, Dang HQ, Vaid N, Tuteja N. Isolation of high salinity stress tolerant genes from Pisum sativum by random overexpression in Escherichia coli and their functional validation. Plant Signal Behav. 2009;4(5):400-12.

93. Liu DD, Sun XS, Liu L, Shi HD, Chen SY, Zhao DK. Overexpression of the melatonin synthesis-related gene SICOMT1 improves the resistance of tomato to salt stress. Molecules. 2019;24(8):1514.

94. Liu DG, He SZ, Song XJ, Zhai H, Liu N, Zhang DD, Ren ZT, Liu QC. IbSIMT1, a novel salt-induced methyltransferase gene from Ipomoea batatas, is involved in salt tolerance. Plant Cell Tissue Org Cult. 2015;120(2):701-15.

95. Wang M, Zhu X, Wang K, Lu C, Luo M, Shan T, Zhang Z. A wheat caffeic acid 3-O-methyltransferase TaCOMT-3D positively contributes to both resistance to sharp eyespot disease and stem mechanical strength. Sci Rep. 2018;8(1):1-14.

96. $\mathrm{Ma} \mathrm{QH}$. The expression of caffeic acid 3-O-methyltransferase in two wheat genotypes differing in lodging resistance. J Exp Bot. 2009:60(9):2763-71.

97. Wu X, Wu J, Luo Y, Bragg J, Anderson O, Vogel J, Gu YQ. Phylogenetic, molecular, and biochemical characterization of Caffeic acid omethyltransferase gene family in Brachypodium distachyon. Int J Plant Genom. 2013;2013(5-6):423189.

98. Hsu C-Y, MAA II, Miao Q, Saha S, Jenkins JN, Ayubov MS, Abdurakhmonov IY, Peterson DG, Ma D-P. Transcriptome analysis of ten days post Anthesis elongating Fiber in the upland cotton (Gossypium hirsutum) chromosome substitution line CS-B25. Am J Plant Sci. 2018;9:1334-61.

99. Bhardwaj R, Handa N, Sharma R, Kaur H, Kohli S, Kumar V, Kaur P. Lignins and abiotic stress: an overview. In: Ahmad P, Wani M, editors. Physiological mechanisms and adaptation strategies in plants under changing environment. New York: Springer; 2014. p. 267-96.

100. Han LB, Li YB, Wang HY, Wu XM, Li CL, Luo M, Wu SJ, Kong ZS, Pei Y, Jiao $G L$, et al. The dual functions of WLIM1a in cell elongation and secondary wall formation in developing cotton fibers. Plant Cell. 2013; 25(11):4421-38

101. Zhu T, Liang C, Meng Z, Sun G, Meng Z, Guo S, Zhang R. CottonFGD: an integrated functional genomics database for cotton. BMC Plant Biol. 2017; 17(1):1-9.

102. Cao J, Schneeberger K, Ossowski S, Günther T, Bender S, Fitz J, Koenig D, Lanz C, Stegle O, Lippert C. Whole-genome sequencing of multiple Arabidopsis thaliana populations. Nat Genet. 2011:43(10):956.

103. Argout X, Salse J, Aury J-M, Guiltinan MJ, Droc G, Gouzy J, Allegre M, Chaparro C, Legavre T, Maximova SN. The genome of Theobroma cacao. Nat Genet. 2011;43(2):101-8.

104. Finn RD, Clements J, Eddy SR. HMMER web server: interactive sequence similarity searching. Nucleic Acid Res. 2011;39(suppl_2):W29-37. 
105. Larkin MA, Blackshields G, Brown NP, Chenna R, McGettigan PA, McWilliam $H$, Valentin F, Wallace IM, Wilm A, Lopez R. Clustal W and Clustal X version 2.0. Bioinformatics. 2007;23(21):2947-8.

106. Kumar S, Stecher G, Tamura K. Evolution: MEGA7: molecular evolutionary genetics analysis version 7.0 for bigger datasets. Mol Biol. 2016;33(7):1870-4.

107. Hu B, Jin J, Guo A-Y, Zhang H, Luo J, Gao G. GSDS 2.0: an upgraded gene feature visualization server. Bioinformatics. 2015;31(8):1296-7.

108. Bailey TL, Boden M, Buske FA, Frith M, Grant CE, Clementi L, Ren J, Li WW, Noble WS. MEME SUITE: tools for motif discovery and searching. Nucleic Acid Res. 2009:37(suppl_2):W202-8.

109. Lescot M, Déhais P, Thijs G, Marchal K, Moreau Y, Van de Peer Y, Rouzé $P$, Rombauts S. PlantCARE, a database of plant cis-acting regulatory elements and a portal to tools for in silico analysis of promoter sequences. Nucleic Acids Res. 2002;30(1):325-7.

110. Yu CS, Chen YC, Lu CH, Hwang JK. Prediction of protein subcellular localization. Proteins Struct Function Bioinform. 2006;64(3):643-51.

111. Kanehisa M, Goto S. KEGG: Kyoto encyclopedia of genes and genomes. Nucleic Acids Res. 2000;28(1):27-30.

112. Carbon S, Ireland A, Mungall CJ, Shu S, Marshall B, Lewis S, Hub A, Group WPW. AmiGO: online access to ontology and annotation data. Bioinformatics. 2009;25(2):288-9.

113. Jamshed M, Jia F, Gong J, Palanga KK, Shi Y, Li J, Shang H, Liu A, Chen T, Zhang Z, et al. Identification of stable quantitative trait loci (QTLS) for fiber quality traits across multiple environments in Gossypium hirsutum recombinant inbred line population. BMC Genomics. 2016;17:197.

114. Sun F-D, Zhang J-H, Wang S-F, Gong W-K, Shi Y-Z, Liu A-Y, Li J-W, Gong J-W, Shang H-H, Yuan Y-L. QTL mapping for fiber quality traits across multiple generations and environments in upland cotton. Mol Breed. 2012;30(1):569-82.

115. Rychlik W. OLIGO 7 primer analysis software. In: PCR primer design. Springer; 2007. p. 35-59.

116. Livak KJ, Schmittgen TD. Analysis of relative gene expression data using real-time quantitative $P C R$ and the $2-\Delta \Delta C T$ method. Methods. 2001;25(4): 402-8.

\section{Publisher's Note}

Springer Nature remains neutral with regard to jurisdictional claims in published maps and institutional affiliations.

Ready to submit your research? Choose BMC and benefit from:

- fast, convenient online submission

- thorough peer review by experienced researchers in your field

- rapid publication on acceptance

- support for research data, including large and complex data types

- gold Open Access which fosters wider collaboration and increased citations

- maximum visibility for your research: over $100 \mathrm{M}$ website views per year

At $\mathrm{BMC}$, research is always in progress.

Learn more biomedcentral.com/submissions 